\title{
Polyploidy affects growth, fillet composition, and fatty acid profile in two year old rainbow trout, Oncorhynchus mykiss
}

Jeremy Lynn Everson

Follow this and additional works at: https://researchrepository.wvu.edu/etd

\section{Recommended Citation}

Everson, Jeremy Lynn, "Polyploidy affects growth, fillet composition, and fatty acid profile in two year old rainbow trout, Oncorhynchus mykiss" (2015). Graduate Theses, Dissertations, and Problem Reports.

5560.

https://researchrepository.wvu.edu/etd/5560

This Thesis is protected by copyright and/or related rights. It has been brought to you by the The Research Repository @ WVU with permission from the rights-holder(s). You are free to use this Thesis in any way that is permitted by the copyright and related rights legislation that applies to your use. For other uses you must obtain permission from the rights-holder(s) directly, unless additional rights are indicated by a Creative Commons license in the record and/ or on the work itself. This Thesis has been accepted for inclusion in WVU Graduate Theses, Dissertations, and Problem Reports collection by an authorized administrator of The Research Repository @ WVU. For more information, please contact researchrepository@mail.wvu.edu. 
Polyploidy affects growth, fillet composition, and fatty acid profile in two year old female rainbow trout, Oncorhynchus mykiss

\author{
Jeremy Lynn Everson
}

Thesis submitted to the

Davis College of Agriculture, Forestry, and Design

at West Virginia University

In partial fulfillment of the requirements

for the degree of

Master of Science

in

Animal and Nutritional Sciences

P. Brett Kenney, Ph.D., Chair

Eugene E. Felton, Ph.D.

Janet Tou, Ph.D.

Division of Animal and Nutritional Sciences

Morgantown, West Virginia

2015

Key words: Rainbow trout, maturation, ploidy induction, composition, fatty acids 


\title{
Polyploidy affects growth, fillet composition, and fatty acid profile in two year old female rainbow trout, Oncorhynchus mykiss
}

\section{Jeremy Lynn Everson}

\begin{abstract}
Gonadal development is a dominant physiological process that alters growth and fat metabolism, thereby reducing fillet quality. Sterile, triploid (3N) female rainbow trout, generated by pressure-induced shock of zygotes 30 minutes after fertilization (3NP), are used to eliminate reduced growth and quality associated with gonadogenesis. However, this method does not produce $100 \% 3 \mathrm{~N}$ offspring. Crossing a diploid (2N; fertile) female and a tetraploid (4N; fertile) male produces triploid offspring $100 \%$ of the time (3NC; sterile). This method is not widely used in the industry because it requires $4 \mathrm{~N}$ brood stock. The current study examines growth, fatty acid composition, and fillet quality attributes, just prior to ovulation for diploid (2N), pressureinduced triploid (3NP), or naturally-produced triploid (3NC) females. As an indication of growth rate, $3 \mathrm{NC}(2109.2 \mathrm{~g})$ fish were heavier followed by $2 \mathrm{~N}(1826.3 \mathrm{~g})$ and $3 \mathrm{NP}(1524.2 \mathrm{~g})$ individuals $(\mathrm{p}<0.05)$. Separable muscle as a percent whole body weight was higher $(\mathrm{p}<0.05)$ in $3 \mathrm{NC}(46.5 \%)$ followed by the 3NP $(43.6 \%)$, and both methods of triploid induction were higher compared to the $2 \mathrm{~N}(38.3 \%)$ individuals. These measurements indicate that larger fish do not yield the highest proportion of muscle. The $3 \mathrm{NC}$ fillets contained more $(\mathrm{p}<0.05)$ intramuscular crude fat followed by the $3 \mathrm{NP}$ and $2 \mathrm{~N}$ fillets $(13.4 \%, 11.2 \%, 8.17 \%$, respectively). Our data demonstrate the inverse relationship between moisture and fat content; moisture content was highest $(\mathrm{p}<0.05)$ in the $2 \mathrm{~N}$ followed by the $3 \mathrm{NP}$ and $3 \mathrm{NC}(72.3 \%, 68.8 \%, 66.7 \%$, respectively). Based on relative peak area, $2 \mathrm{~N}$ fillets contained $(\mathrm{p}<0.05)$ fewer saturated fatty acids (SFA, $29.2 \%$ ) compared to $3 \mathrm{NC}(34.9 \%)$ and $3 \mathrm{NP}(33.4 \%)$ fillets; diploids mobilized stored SFA for egg development. Moreover, $2 \mathrm{~N}$ fillets contained more $(\mathrm{p}<0.05)$ polyunsaturated fatty acids (PUFA, 28.7\%) compared to 3NC and 3NP (2.6\% and 24.8\%, respectively). 3NC and 3NP muscle had higher $(\mathrm{p}<0.05)$ levels of $\mathrm{C} 12: 0, \mathrm{C} 14: 0$, compared to $2 \mathrm{~N}$ animals. Fatty acids $\mathrm{C} 16: 0$ and 16:1 were highest $(\mathrm{P}<0.05)$ in $3 \mathrm{NC}$ compared to other ploidies. Albeit, $2 \mathrm{~N}$ muscle contained more $(\mathrm{p}<0.05) \mathrm{C} 22: 6 \mathrm{n} 3, \mathrm{C} 20: 3 \mathrm{n} 6$ and $\mathrm{C} 18: 1 \mathrm{n} 9 \mathrm{c}$ compared to $3 \mathrm{NC}$ and $3 \mathrm{NP}$. Linoleic acid $(18: 2 n 6 c)$ was highest in $2 \mathrm{~N}$ followed by $3 \mathrm{NP}$ then $3 \mathrm{NC}$ muscle $(\mathrm{p}<0.05)$. To determine if fatty acids were preferentially mobilized from triglyceride or phospholipids, TLC plates were used to separate lipid classes; ploidy did not affect ( $>>0.05)$ fatty acids present in triglyceride and phospholipids. However, when comparing lipid classes the data indicated that the triglycerides had higher levels of C16:1, C18:1n9c, C18:2n6c, C18:3n3 and C22:1n9 when compared to the phospholipids. While phospholipids contained higher levels of C16:0, C20:4n6, C20:5n3, and $\mathrm{C} 22: 6 \mathrm{n} 3$. Most notably phospholipids contained 3 times the level of C22:6n 3 docosahexanoic acid (DHA) compared to triglycerides. DHA is known for its important role in maintaining the structure and function of cellular membranes. Overall, naturally produced triploids (3NC)
\end{abstract}


exhibited superior growth and fillet yields, and method of triploid production did not affect fatty acid profile of intramuscular lipid stores with the exception of C18:2n6c, C16:0, and C16:1. 


\section{ACKNOWLEDGEMENTS}

First and foremost I would like to thank my parents, Mark and Kim Everson. They have always been there for me with nothing less than the upmost support I could ever ask for. I will always be indebted to the love that they have shown to me. I would also like to take this time to recognize my extended family that have been there to encourage me embrace me throughout this journey. Next I would like to thank Dr. Brett Kenney for his willingness to provide me with this opportunity and for being more than an advisor to me but also a true friend. His support has given me the confidence to handle any task given. I would like to take this time to thank my committee members, Dr. Eugene E. Felton and Dr. Janet Tou for support and guidance in this study. I would also like to thank Meghan Manor, Susan Slider for their assistance in conducting laboratory projects and statistical analysis.

This study would not have been possible without the seamless collaboration with the National Center for Cool and Cold Water Aquaculture (NCCCWA) in Leetown, West Virginia. I would like to especially thank Greg Weber for allowing me to conduct this study with a data set generated from fish within one of his many projects. I would like to express my gratitude to all the facilities employees for the opportunity and their help in rearing and care of the fish. Moreover I would like to thank everyone that who has supported me throughout my journey and express how grateful I am to have made so many lifelong friends throughout the journey. 


\section{TABLE OF CONTENTS}

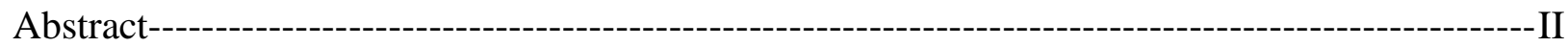

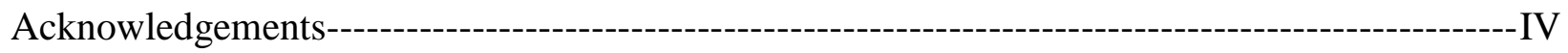

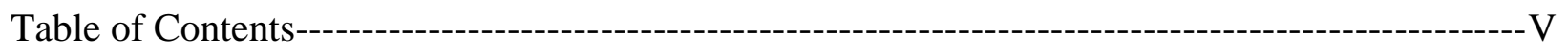

List of Tables-------

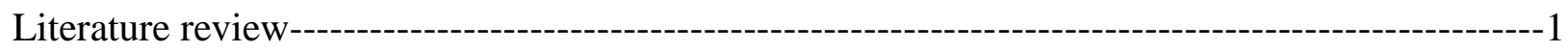

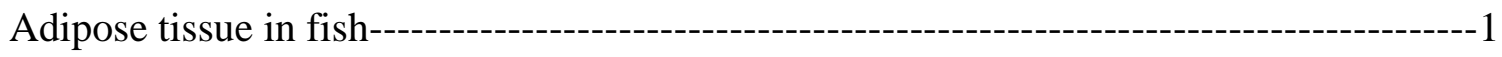

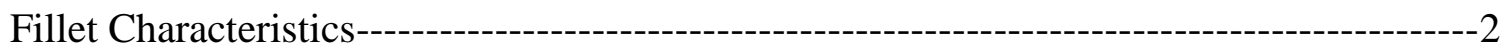

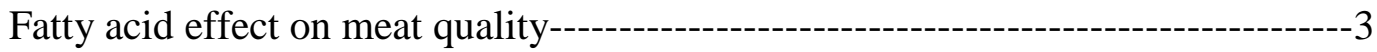

Proximate composition-------------------------------------------------------------4

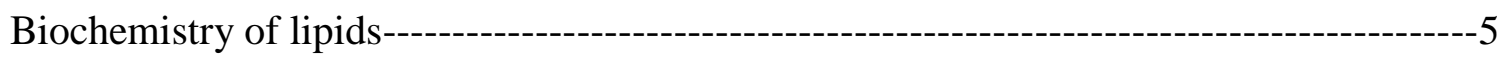

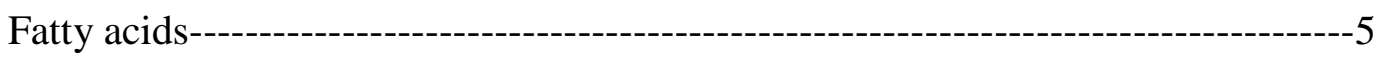

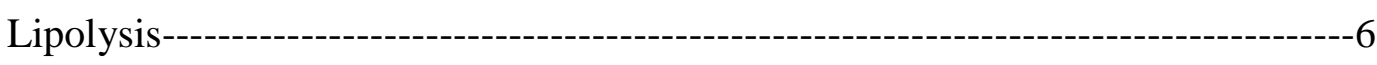

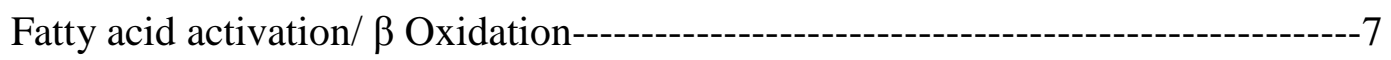

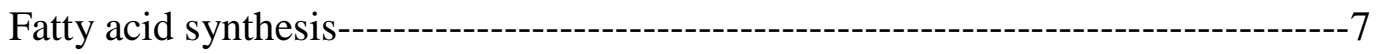

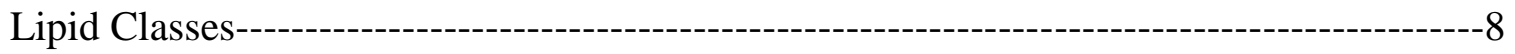

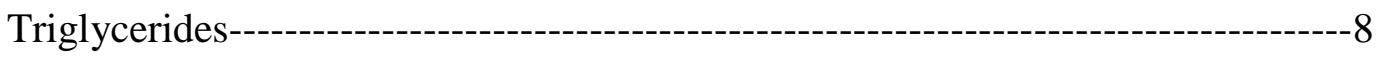

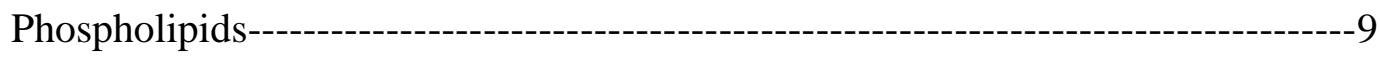

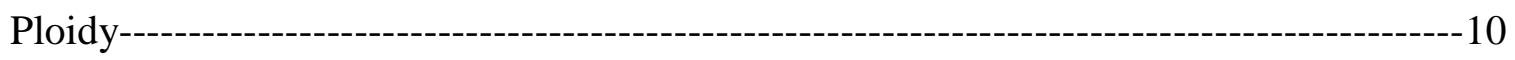

Polyploidy induction methods in rainbow trout-----------------------------------11

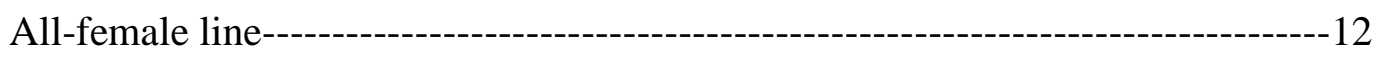

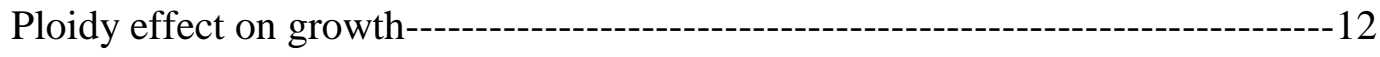

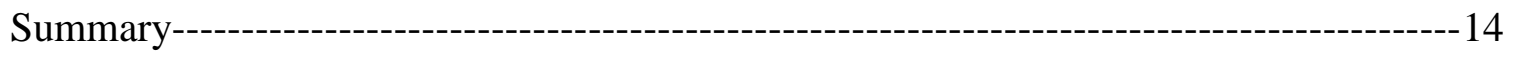

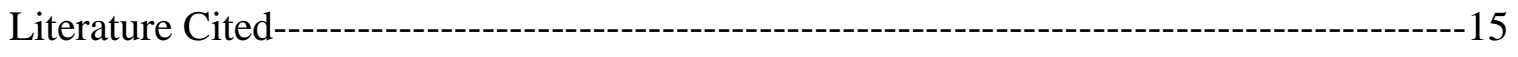




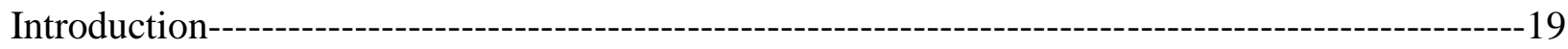

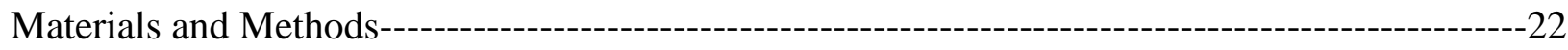

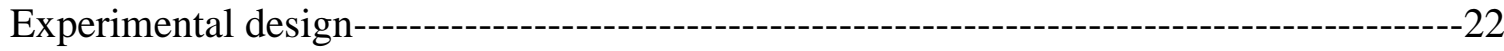

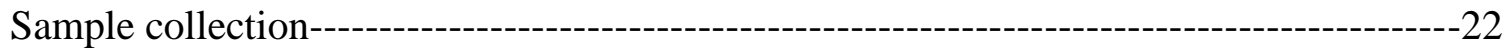

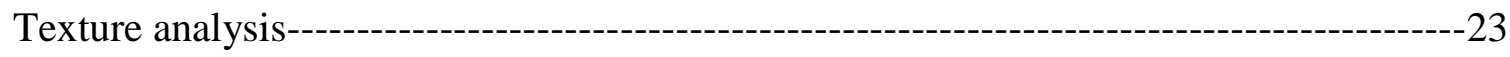

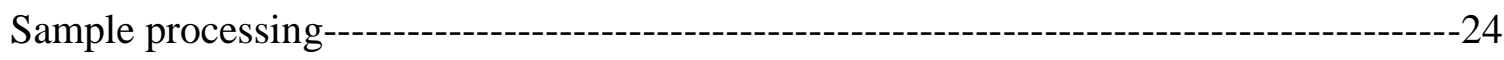

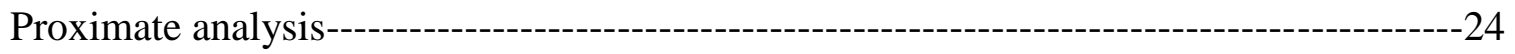

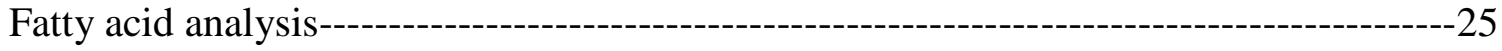

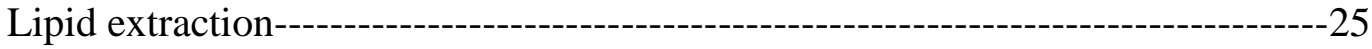

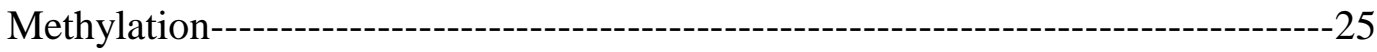

Separation and quantification------------------------------------------------------------26

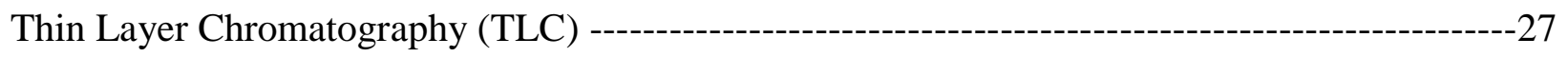

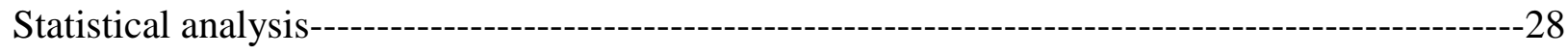

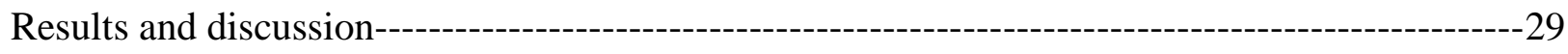

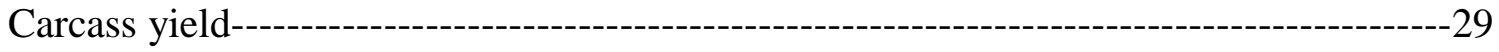

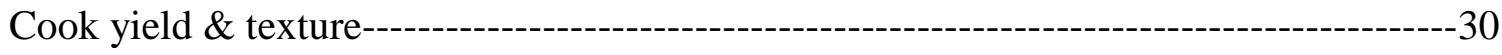

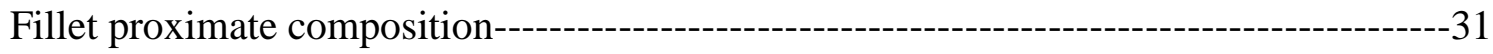

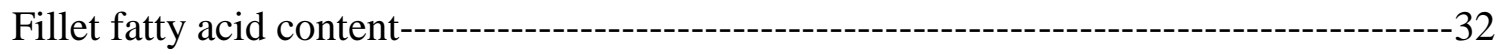

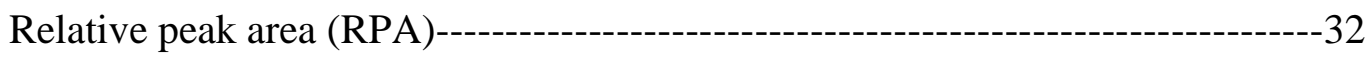

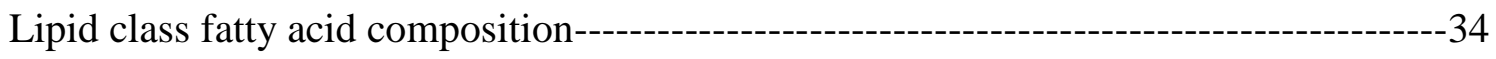

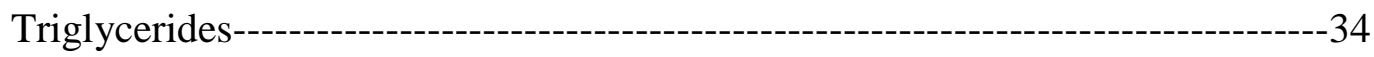

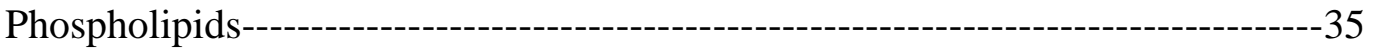

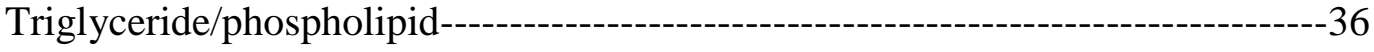

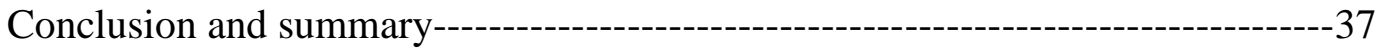

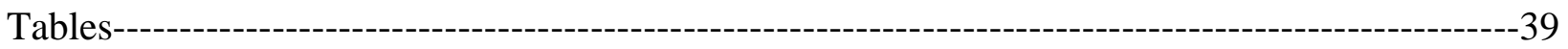




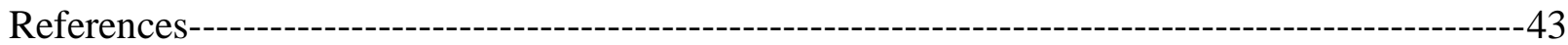

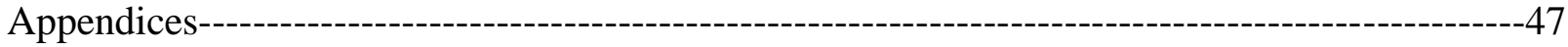

1.) Lipid extraction and fatty acid methylation-------------------------------------47

2.) Calculations for proximate analysis----------------------------------------50

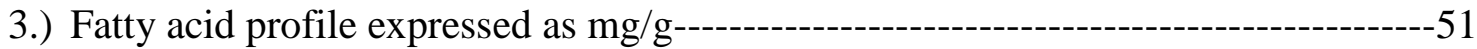




\section{LIST OF TABLES}

1.) Effects of ploidy on carcass yield and proximate composition-----------------------39

2.) Effects of ploidy on fatty acid composition of intramuscular lipids based on relative peak

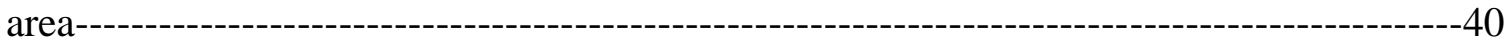

3.) Effects of ploidy on intramuscular fatty acid composition within triglycerides------------41

4.) Effects of ploidy on intramuscular fatty acid composition within phospholipids----------41

5.) Intramuscular fatty acid composition as affected by lipid class---------------------------42 


\section{LITERATURE REVIEW}

The high energy production of gonads in a mature fish account for twenty five percent of the fish's whole body weight. Therefore, if the high energy expended could be designated to muscle growth rather than sexual development, producers could keep fish in production cycles longer (Johnston et al., 1999). To avoid these degradative results of maturation, producers turn to triploids. Triploid (3N) rainbow trout are desired for production because triploids are steril, have superior filet quality and overall growth, and improved feed conversion when compared to diploids $(2 \mathrm{~N})$.

\section{Adipose tissue in fish}

Lipids are the predominant source of stored energy in fish. Fish store lipid in adipose tissue located at different regions of the body and this lipid, particularly intramuscular stores, plays an important role in product quality. Subcutaneous and peri-visceral adipose tissues influence fillet yields, while muscle deposits affect organoleptic quality of the fillet (Weil et al., 2013). The major fat deposits in fish are the peri-visceral, intramuscular, and liver (Sheridan, 1998) stores. The different fat deposits that influence carcass quality can be roughly divided into discarded and consumed fat. The discarded fat deposits include visceral fat, located in the body cavity, and subcutaneous that lies under the skin. Discarded, subcutaneous fat is most prominent in the dorsal and ventral regions; ventral deposits are primarily the belly flaps, located on either side of the ventral midline. Weil et al. (2013) found that subcutaneous dorsal adipose tissue was 1.6 times lower than the fat tissue present in the belly flap of periovulated and postovulated rainbow trout. Consumed fats include those present in white and red muscle, and 
white muscle makes up $90 \%$ of the muscle found in fish (Johnston, 1981). Therefore, white muscle is the focus of commercial production.

Adipose tissue regulation and development can be influenced by extrinsic and intrinsic factors. Various extrinsic factors include temperature, salinity, water quality, photoperiod, availability of nutrients, and digestibility of nutrients. Fish fed a high plane of nutrition, that place the fish in a positive energy balance, exhibit hyperplasia and hypertrophy of adipocytes. These effects result in larger belly flaps and decreased water content without modifying protein content of the fillets (Weil et al., 2013). Fat deposition is also influenced by intrinsic factors such as genotype, growth, and reproductive stages. Watanabe et al. (1988) showed that triploid female ayu had higher rates of fat accumulation than diploids. During sexual maturation, diploid rainbow trout exhibited decreased fillet fat content compared to triploids (Aussanasuwannakul et al., 2011). Relative to fish age, fat content increases with size (Weil et al., 2012). During reproduction, lipid content increased significantly at the start of gonadogenesis and spermatogenesis. Lipid content plateaued at full spermatogenesis and vitellogenesis follow by a decrease in intramuscular lipid during ovulation and spermiation (Weil et al., 2013). Nassour et al. (1989) found that approximately $18 \%$ of lipids mobilized during sexual maturation were directed toward the ovaries.

\section{Fillet characteristics}

Fillet size and quality are the primary interests of commercial food-fish producers. In rainbow trout, the consumed portion represents less than half the live weight of the fish (Bugeon et al., 2010). Aussanauwannakul et al. (2011) found mature triploids had 1.04 times higher muscle yield (percent empty body weight), than mature diploids of the same age. Thus, one way 
to produce higher fillet weight is with triploids. Triploids can have extended endpoints past spawning where diploids encounter the previous aforementioned degradative effects of sexual maturation. Additionally, triploids do not have developing gonads that are discarded and consequently reduce separable muscle yield. Salem et al. (2006) saw an $11 \%$ reduction in separable muscle of diploids during sexual maturation when compared to triploids. However, when fish were fed at a high plane of nutrition, diploids are better able to maintain fillet mass during sexual maturation (Aussanauwannakul et al., 2011). Texture, often an accepted method of fillet quality, is affected by many enzymatic and chemical reactions. These reactions lead to changes in softness, elasticity, and toughness of the fillet (Coppes et al.,2002). Immobilized free water and neutral lipids tend to dilute the structural elements of muscle and decrease overall mechanical strength of meat (Dunajski, 1979). Aussanauwannakul et al. (2001) stated that muscle containing more fats was found to be more tender, while in lean species, tenderness increased with water content. Diploid fish produced tougher fillets $(\mathrm{g} / \mathrm{g})$ during spawning season compared to two months prior (Aussanauwannakul et al., 2011).

Fatty acid effect on meat quality Fatty acid type and amount can affect fillet quality. Overall tenderness and juiciness of meat is influenced by fat content. However, as fatty acid unsaturation increases, melting point decreases, reducing the firmness of the meat. Wood et al. (2003) found that in monogastric animals that stearic acid (C18:0) hardens the meat while linoleic acid (C18:2) softened the meat. Excessive levels of omega-3 fatty acids, such as docosahexaenoic acid (DHA) are known to adversely influence flavor and color (Wood et al., 2003). Unsaturated fatty acids can decrease shelf life of the product because of their susceptibility to autoxidation. Lipid oxidation affects color and rancidity by increasing the rate 
of myoglobin oxidation, causing color to change from red to brown have been found within terrestrial animals (Wood et al., 2003).

Proximate composition: Information on fillet composition will help the commercial processor determine optimal processing and storage conditions to achieve maximum quality and fillet yield. This information will also enable the aquaculture producer to define more precisely, optimal age and weight, and harvest endpoints. The four major components that contribute to the edible portion of the fillet are water, lipid, protein, and ash (minerals). Water is the most abundant of the four components comprising 60-90\% of the tissue. Water and lipid content is inversely related; therefore, fillets containing more lipid also contain less water (Bolawa et al., 2011). Fish fed at a high plane of nutrition tend to have less water present ranging from $60-70 \%$ (Aussanauwannakul et al., 2011). Lipid accumulation in the fillet varies depending upon nutrients fed and time of maturation. Dunham (2011), found that during spawning lipid content of fillets from triploid females was three times higher than that of fillet from diploids because diploids mobilized lipid to support sexual maturation. Aussanauwannakul et al. (2011), found that diploids fed on a high plane of nutrition averaged approximately $6 \%$ fat, and triploids, under the same conditions, averaged $12 \%$ fat.

Protein is the second highest chemical component of muscle tissue and continues to keep growing interest to producers. Protein in fish fillets ranges from 12-22\%, with anything less than $15 \%$ being considered low (Dunham, 2011). Ash is the smallest component of muscle proximate composition. Ash content can range from 1-5\% within the fillet. Dunham (2011) found that, when compared to diploids, triploids had the highest mineral composition. 


\section{Biochemistry of lipids}

Fatty acids: Oils within fat are the principle storage form of energy in many organisms, including fish. The storage form of these oils within fat is fatty acids. Fatty acids are carboxylic acids with varying length hydrocarbon chains. Fatty acids that contain hydrocarbon chains with one or more double bonds are known as unsaturated fatty acids, and hydrocarbon chains with no double bonds are fully saturated (Nelson and Cox, 2013). The ability of these lipids to pack into a lipid molecule largely depends on the degree of unsaturation. Saturated fatty acids align with polar heads in one direction and that allows their nonpolar hydrocarbon chains to pack tightly. Unsaturated fatty acids, because of the kink in their lipid chain, do not pack tightly. Due to this inability to pack tightly, less energy is required to break apart these unsaturated fatty acids thus unsaturated fats have a lower melting point (Nelson and Cox, 2013). Since unsaturated fatty acids have the double bond that adds a bend in the hydrocarbon chain, the hydrogens on the double bond can exist in a cis or trans orientation, resulting in cis and trans isomers. There are a variety of desaturations that can occur from monounsaturated acids (MUFA) to polyunsaturated fatty acids (PUFA) to highly unsaturated fatty acids (HUFA). A monounsaturated fatty acid contains only one double bond. The most abundant monounsaturated fatty acids in fish are 20:1n9 and 22:1n-11 (Ackman, 1989). Polyunsaturated fatty acids contain more than one double bond. The main polyunsaturated fatty acids in fish are 20:4n-6 (arachidonic acid, AA), AA's metabolic precursor 18:2n-6 (linoleic acid), 20:5n-3 (eicosapentaenoic acid, EPA), and 22:6n-3 (docosahexaenoic acid, DHA); the metabolic precursor both EPA and DHA is $18: 3 n-3$ ( $\alpha$ linolenic) (Tocher, 2003). All vertebrates, including fish, lack $\Delta 12$ and $\Delta 15$ desaturases; consequently they cannot form 18:2n-6 and 18:3n-3 from 18:1n-9 (Tocher,2003). Therefore, 18:2n-6 and 18:3n-3 are essential dietary fatty acids. 
Lipolysis: Once dietary fat travels through the stomach and reaches the gall bladder, fat is first emulsified by bile salts that form mixed micelles. Fatty acid and other breakdown products are taken up by the intestinal mucosa and converted to triacylglycerides. These triglycerides are packaged with cholesterol and apolipoproteins into chylomicrons (Nelson and Cox, 2013). Chylomicrons subsequently move through the lymphatic system and bloodstream where lipoprotien lipase converts triacylglycerols to fatty acids and glycerol. These fatty acids are then oxidized for fuel or reesterfied for storage (Staver et al., 2012). Following storage and when needed for energy, fatty acids are hydrolyzed through the process of lipolysis. Lipolysis begins as low levels of glucose cause the release of glucagon that binds to its receptor on an adipocyte. This stimulates adenyl cyclase by the form of a $\mathrm{G}_{\mathrm{s}}$ protein, which serves as an intermediary between hormone receptor and effector enzymes, to produce cAMP from ATP (Nelson and Cox, 2013). Release of cAMP activates protein kinase A (PKA); this enzyme catalyzes phosphorylation of hormone-sensitive lipase (HSL) and perilipin (Michelsen et al., 1993). Once perilipin is phosphorylated by HSL, it then causes dissociation of comparative gene identification- 58 (CGI-58) from perilipin (Yamaguchi et al.,2007). Once CGI is released, it binds with adipose triacylglycerol lipase (ATGL) that converts triacylglycerols to diacylglycerols. Phosphorylation of HSL allows HSL to access the lipid droplet where it then converts diacylglycerols to monoacylglycerols. The third and final fatty acid on the triglyceride is hydrolyzed by monoacylglycerol lipase (MGL) (Nelson and cox, 2013). Following complete hydrolysis of three fatty acids from the triglyceride, these fatty acids leave the adipocyte and bind with serum albumen. The bound fatty acids are carried through the blood stream to various tissues throughout the body. 
Fatty acid activation/ $\boldsymbol{\beta}$ Oxidation: Generation of ATP from fatty acids is known as fatty acid oxidation. Fatty acid oxidation requires three critical components that consist of $\beta$ oxidation, the citric acid cycle, and respiratory electron transfer chain. The first and rate limiting step of $\beta$ oxidation is catalyzed by carnitine acyltransferase- 1 . Carnitine acyltransferase- 1 facilitates transport of fatty acyl-CoA from the cytosol though the inner and outer mitochondrial membrane to the matrix. During $\beta$ oxidation and cleavage of 2 -carbon units from the fatty acid chain, acetyl-CoA is generated until the last acetyl-CoA remains. (Nelson and Cox, 2013). For every two-carbon unit cleaved, acetyl-CoA, $\mathrm{FADH}_{2}, \mathrm{NADH}$ plus $\mathrm{H}^{+}$are produced. Acetyl-CoA groups generated from $\beta$ oxidation are sent through the citric acid cycle (Voet and Voet, 2004). One acetyl-CoA enters the citric acid cycle, which consists of eight enzymatic reactions, and it produce three molecules of $\mathrm{NADH}$, two molecules of $\mathrm{FADH}_{2}$ and GDP, and releases 2 molecules of $\mathrm{CO}_{2}$ through one cycle. Reduced cofactors, $\mathrm{NADH}$ and $\mathrm{FADH}_{2}$, that are produced by the citric acid cycle move to the electron transport chain where oxygen serves as the final electron acceptor in regenerating $\mathrm{NAD}^{+}$and $\mathrm{FAD}^{+}$. The electron transport chain consists of four complexes that shuttle electrons across membrane gradients to produce energy that is coupled to the phosphorylation of ADP and generates ATP at complex four (Nelson and Cox, 0213).

Fatty Acid Synthesis: The first step in fatty acid biosynthesis is the rate limiting step of acetyl-CoA carboxylase that catalyzes the conversion of acetyl-CoA to malonyl-CoA. Production of malonyl-CoA downregulates carnitine acyl-transferase 1 of $\beta$ oxidation so that fatty acids are not being oxidized as they are produced (Nelson and Cox, 2013). Once malonylCoA donates two carbons to an activated acyl group, the acyl chain extends by two carbons. This process continues until the 16-carbon palmitate is formed. Throughout fatty acid synthesis, it takes one acetyl-CoA, seven molecules of malonyl-CoA, and fourteen molecules of NADPH 
and $\mathrm{H}^{+}$complexes to yield one palmitate, fourteen $\mathrm{NADP}^{+} \mathrm{S}$ and six $\mathrm{H}_{2} \mathrm{Os}$ (Nelson and Cox, 2013). Once palmitate is produced, which is then desaturated and elongated by specific enzymes to reach the desired fatty acid. Fatty acids shorter than 16 carbons are synthesized by incomplete $\beta$ oxidation of palmitate (Voet and Voet, 2004).

\section{Lipid Classes}

Triglycerides: Triglycerides are the storage form of energy for the organism. Tocher (2003), found that lipid is initially mobilized in adipose tissue; however, during extended periods of energy need, lipid will also be mobilized from secondary storage sites in the liver and muscle. The primary, long-term energy storage site in most fish is the mesenteric adipose tissue. Fish also store fat in white muscle adipose tissue within the myosepta, a connective tissue sheath that lies perpendicular to the muscle fiber and separates myomeres (Henderson et al., 1987). Fish also store large amounts of triglycerides subcutaneously. During feeding, excess dietary fatty acids are exported from the liver, in the form of very low density lipoprotein (VLDL), and these fatty acids are stored in the form of triacylglycerols in specific lipid storage locations. Apart from starvation, an example of when fish mobilize these lipid stores is during reproduction, particularly during gonadogenesis, an energetically demanding process. (Tocher, 2003) Dunham (2011) found that triploids and diploids in the non-spawning season had a higher level of intramuscular triglycerides compared to diploids in spawning season. In diploid fish, triglyceride fat stores are mobilized for energy needed during sexual maturation. Ringo et al. (1990) found that artic charr did not selectively mobilize triglycerides from skeletal muscle but from the liver. 
De novo triglyceride synthesis in fish has not been studied extensively, but available evidence suggests that the pathways are generally the same in fish as in mammals (Tocher, 2003). In mammalian adipose tissue, glucose travels through glycolysis to the intermediate of dihydroxyacetone phosphate which contains 3 carbon units that get converted by glycerol 3phosphate dehydrogenase to reach L-glycerol 3-phosphate. If triglyceride production occurs in the liver, glycerol is converted to L-glycerol 3-phosphate by glycerol kinase. Subsequently, Lglycerol 3-phosphate is processed by two acyl transferases to reach phosphatidic acid.

Phosphatidic acid is the branching point determining whether the fatty acid will become a triglyceride or a phospholipid. Phosphatidic acid is converted to 1,2 diacylglycerol by phosphatidic acid phosphatase. Lastly, 1, 2 diacylglycerol becomes triacylglycerol via a final, acyl transferase reaction (Nelson and Cox, 2013).

Phospholipids: Phospholipids, in general, are any lipids that contain phosphorus. Synthesis of these phospholipids is essentially the same as triglycerides because they originate from glucose or glycerol. There are various type of phospholipids and differ depending on their beginning structure and the head group attached. Phospholipids are characterized by a common phosphatidic backbone formed from L-glycerol 3-phosphate esterified to two fatty acids (Tocher et al., 2008). Nelson and Cox (2013) indicate that saturated and monounsaturated fatty acids prefer to bond to the phosphoglycerides at sn-1 position while polyunsaturated fatty acids prefer to bond at the sn-2 position. Phospholipids are primary components of the cell membrane as critical constituents of the phospholipid bilayer. Phospholipids possess a hydrophilic region at sn-3 and hydrophobic regions at sn-1 and sn-2 positions; this structure facilitates formation of lipid bilayers in fish as it does in mammals (Tocher et al., 1995). Due to their ampiphilicity and contribution to lipoprotein structure, phospholipids are also important in the extracellular 
transport of lipids in lymph. Phospholipids are the primary substrate for eicosanoid formation (Tocher et al., 1995). Eicosanoids are a range of highly bioactive derivatives of -twenty-carbon, highly unsaturated fatty acids, in particular arachadonic (ARA, 20:4n-6) and eicosapentaenoic acids (EPA, 20:5n-3) (Tocher et al., 1995). Eicosanoids are constituents of many physiological processes, including blood clotting and cardiovascular tone, immune and inflammatory responses, reproduction, and neural functions (Coutteau et al., 1997). Phospholipids main role is to add fluidity to cell membranes. Mobilization of hepatic phospholipids to free fatty acids to support gonadal growth was found in catfish (Arts et al., 1999). Dunham (2011) reported that phospholipids were lower in triploid fish and diploid fish outside of spawning season than diploid fish during spawning. Higher levels of phospholipids in diploids might be explain by the fact they have smaller cell, therefore they will have more lipid membrane present in a given area than triploids which have increased cell size and will have fewer cells present in that same given area. Triglycerides are the lipid class whose primary function is lipid storage; nonetheless phospholipids can also be used as a source of energy during embryonic and early larval development (Tocher et al., 1995).

\section{$\underline{\text { Ploidy }}$}

To avoid the negative effects associated with sexual maturation, triploid fish are desired over diploids. Therefore, triploid fish are able to deposit muscular growth while diploids focus on gonadal development during maturation. In farm-raised fish, maturation marks the end of the useful rearing period if the producer wants to realize maximum fillet yields (Johnston et al., 1999). At spawning or the completion of gonadogenesis, the gonads may account for twentyfive percent of body weight in a mature fish. Therefore, if the energetic demand of this process could be directed to muscle growth rather than sexual development, producers could keep fish in 
production cycles longer (Johnston et al., 1999) and realize greater profit. Consequently, use of sterile, triploid ( $3 \mathrm{~N})$ fish has merit because the production cycle is extended without the negative effects of gonadogenesis on growth efficiency and fillet yield and quality. Manipulation of cell division to generate $3 \mathrm{~N}$ individuals is designed to block extrusion of the second polar body during meiosis resulting in two sets of chromosomes from the mother and one from the father (Tiwary et al., 2004). Another advantage is triploid fish are not an environmental threat in the event of escapement because as these individuals are sterile they cannot breed with wild counterparts.

Polyploid Induction Methods in Rainbow Trout: There are two general ways to produce a triploid fish, naturally or with induced shock from pressure or temperature manipulation. Data suggest that method of ploidy induction affects the growth potential of the fish. First, pressure shock or temperature shock can be applied to the zygote during meiosis. When utilizing pressure shock, $9,000 \mathrm{lb} / \mathrm{in}^{2}$ of pressure is applied thirty minutes post fertilization for eight minutes (Hershberger et al., 2007). Triploid production using pressure can have deleterious effects on the offspring because the shock induces early, developmental stage trauma within the eggs (Weber et al., 2014). Alternatively, temperature shock is performed twenty minutes post fertilization, and the eggs are immersed in a thermoregulated water bath at $26^{\circ} \mathrm{C}$ for twenty minutes (Solar et al., 1984).

Beyond shock induction, diploid ( $2 \mathrm{~N})$ individuals can be crossed with tetraploids $(4 \mathrm{~N})$ to produce triploid $(3 \mathrm{~N})$ offspring, naturally. This method is ideal because producers are guaranteed 100\% triploid offspring (3NC) (Hershberger et al., 2007). The challenge with this approach is the difficulty in producing the male tetraploid parent. To obtain a tetraploid, a force at 9,000 $\mathrm{lb} / \mathrm{in}^{2}$ pressure is applied at $62-65 \%$ first mitotic cleavage (Hershberger et al., 2007). 
Timing of proper mitotic cleavage is often difficult to achieve, therefore limiting the number of facilities that can accurately time the cleavage to produce tetraploid lines. Horstgen-Schwark (1993) reported that this method of production results in low hatch and survival rates.

Different methods of triploid production result in different success rates. Producing triploids by shock, while capable of yielding 100\% triploids, has challenges that could cause the success to be less that $100 \%$. To verify triploidy induction, a flow cytometer is used (Allen, 1982). This process measures individual cells, particularly cell nucleus, to determine ploidy by quantifying the amount of light that passes through each egg (Tiwary et al., 2004).

All-Female lines: For aquaculture production, all 3N-female lines are desired. Male triploids still suffer from degradative changes associated with maturation; they are functionally sterile but still produce typical level of androgens during spawning (Johnston et al. 1999). Triploid females are functionally and hormonally sterile due to differences in the architecture of germinal and endocrine tissues (Johnston et al., 1999). As in mammals, sex is determined by the presences of the $\mathrm{Y}$ chromosome. However, the presence of the $\mathrm{Y}$ chromosome is easily manipulated. The production of functional testes in genetic females (XX) is as simple as adding feed with various amounts of hormones such as $20 \mathrm{ppm} 11 \beta$ - hydroxyandrostenedione (OHA) (Johnston et al., 1999). These sex reversed females can then be used to fertilize eggs to give an all-female offspring where the (Y) chromosome has been deleted (Johnston et al., 1999).

Ploidy effect on growth: Triploids have greater growth potential associated with their sterility and consequently, reduced gonadal development (Tiwary et al., 2004). Triploids continue to grow and deposit muscle rather than use energy for reproduction. Johnston et al. (1999) found that triploid fish muscle growth is directly affected by the additional number of chromosomes. The $3 \mathrm{~N}$ muscle appears to have fewer, but larger muscle fibers. Werner et al. 
(2008) suggested that triploids, because of their increase in muscle fiber size would be more susceptible to stress of exercise before slaughter possibly resulting in increased anaerobic glycolysis and lactic acidosis. Triploidy effects on growth are variable and could depend on method of induction, husbandry practices and stage of growth (Thorgaard, 1986). Weber et al., (2014) found that triploids produced by pressure grew slower than their diploid counterparts by week 90 of production. After week 86 and once diploids were experiencing the onset of maturation, the growth impotence switched from muscle deposition to gonadal development. At this point, triploids (pressure induced) were depositing muscle, surpassing the diploids in growth at week 90. Triploids produced naturally had a growth equivalent to that of diploid fish from weeks 26-78. Once diploid growth plateaued as a result of sexually maturation, growth of the triploids (pressure) surpassed diploids and these individuals were approximately 500 grams heavier, on the average, by week 98 (Weber et al., 2014).

From a production standpoint, fish of uniform size at a given weight are ideal for harvesting, because most harvest facilities use a mechanical filleting device to separate product from waste. Leary et al. (1985) reported that triploids produced by heat shock were morphologically similar to that of diploids. Albeit, their results do not suggest there are no deleterious effects of triploidy on rainbow trout. Weber et al. (2014) found that triploids produced by pressure had a higher number of deformities than triploids produced by crossing a diploid and tetraploid parent. These deformities had a negative effect on body weight and fork length, but a positive effect on condition factor (Weber et al., 2014). The negative effect may be described as a football shape that creates problems for mechanical filleting machines because they differ from the typical production fish shape that models the regular diploid shape. Thus, 
$3 \mathrm{NC}$ would be better suited for commercial aquaculture where mechanical filleting machines are implemented because they possess the typical diploid body shape.

Triploids, as a whole, have a reduced number of cells of the central nervous system and reduced hormone levels, which would supports reduced responsiveness to various environmental stimuli (Tiwary et al., 2004). Boulanger (1987) reported that triploids are less aggressive during feeding compared to diploids. Weber et al. (2014) found that even though diploid fish consumed more feed than triploid fish, they did not weigh more, and the triploid fish still had a better specific growth rate, suggesting that triploids have a better feed conversion rate than diploids.

\section{$\underline{\text { Summary }}$}

Triploid rainbow trout are better acclimated to commercial aquaculture production. Triploids do not suffer the deteriorating effects associated with the onset of maturation. Of the methods of triploid production, crossing tetraploid $(4 \mathrm{~N})$ male with diploid $(2 \mathrm{~N})$ female provides a successful $100 \%$ way to produce triploid offspring (3NC). However, this is often associated with low hatch rates. Triploids produced by temperature or pressure shock often suffer from stunted growth in the early stages of life, with triploids produced by pressure (3NP) having a greater number of deformities compared to triploid produced by crossing. Information is needed to address the carcass yield data and fatty acid composition differences between triploids

produced by pressure (3NP) and triploids produced by parental crossing (3NC). 


\section{LITERATURE CITED}

Ackman, R. G. 1989. Marine biogenic lipids, fats and oils (Vol. 2). CRC Press.

Ahvaz, Iran. 2012. "Proximate composition of farmed fish, Oncorhynchus mykiss and Cyprinus carpio from Iran." Advances in Environmental Biology 6.11. 2841-2845.

Allen, S. K. 1983. Flow cytometry: assaying experimental polyploid fish and shellfish. Aquaculture, 33(1), 317-328.

Arts, M. T., \& Wainmann, B. C. (Eds.). 1999. Lipids in freshwater ecosystems. Springer Science $\&$ Business Media.

Aussanasuwannakul, A., Kenney, P. B., Weber, G. M., Yao, J., Slider, S. D., Manor, M. L., \& Salem, M. 2011. Effect of sexual maturation on growth, fillet composition, and texture of female rainbow trout (Oncorhynchus mykiss) on a high nutritional plane. Aquaculture, 317(1), 79-88.

Bolawa, O.E., G.O. Gbenle, S.O. Ayodele, O.R. Adewusi, A.O. Mosuro, \& O.S. Apata. 2011. Proximate Composition Properties of Different Fish Species Obtained from Lagos, Nigeria. Journal of Food Safety. 13, 342-344.

Boulanger, Y. (1987) Preliminary results on the growth of sterile rainbow trout (triploidy induced by a pressure shock) in fish culture. Proc. Ann. Meet. Aquacult. Assoc. Can. 1, 5558 .

Bugeon, J., Lefevre, F., Cardinal, M., Uyanik, A., Davenel, A., \& Haffray, P. 2010. Flesh quality in large rainbow trout with high or low fillet yield. Journal of Muscle Foods, 21(4), 702721.

Coppes, Z., Pavlisko, A., \& Vecchi, S. D. 2002. Texture measurements in fish and fish products. Journal of Aquatic Food Product Technology, 11(1), 89-105.

Coutteau, P., Geurden, I., Camara, M. R., Bergot, P., \& Sorgeloos, P. 1997. Review on the dietary effects of phospholipids in fish and crustacean larviculture. Aquaculture, 155(1), 149-164.

Dunajski, E. 1980. Texture of fish muscle. Journal of Texture Studies, 10(4), 301-318.

Dunham, R. A. 2011. Aquaculture and fisheries biotechnology: genetic approaches. CABI. Harwood, J. L. 1988. Fatty acid metabolism. Annual Review of Plant Physiology and Plant Molecular Biology, 39(1), 101-138.

Gerrard, D. and Grant A. "Chapter 7: Adipose Tissue Growth and Development." Principles of Animal Growth and Development. Kendakk/Hunt Publishing Company. 2006. pgs. 119-136. 
Henderson, R. J., \& Tocher, D. R. 1987. The lipid composition and biochemistry of freshwater fish. Progress in lipid research, 26(4), 281-347.

Hershberger, W. K., \& Hostuttler, M. A. 2007. Protocols for more effective induction of tetraploid rainbow trout. North American Journal of Aquaculture, 69(4), 367-372.

Horstegen-Schwark, G. 1993. Initation of tetraploid breeding line development in rainbow trout, Oncorhynchus mykiss (Walbaum). Aquaculture and Fisheries Management 24, 641-652.

Johnston IA. 1981. Structure and Function of Fish Muscles. Symp zool Soc Lond 48:71-113.

Johnston, I.A., Strugnell, G., McCracken, M.L., Johnstone, R. 1999. Muscle growth and development in normal-sex-ratio and all-female diploid and triploid Atlantic Salmon. The Journal of Experimental Biology. 202, 1991-2016.

Leary, R. F., Allendorf, F. W., Knudsen, K. L., \& Thorgaard, G. H. 1985. Heterozygosity and developmental stability in gynogenetic diploid and triploid rainbow trout. Heredity, 54(Pt 2), 219-225.

Michelsen, K. G., Harmon, J. S., \& Sheridan, M. A. 1994. Adipose tissue lipolysis in rainbow trout, Oncorhynchus mykiss, is modulated by phosphorylation of triacylglycerol lipase. Comparative Biochemistry and Physiology Part B: Comparative Biochemistry, 107(4), 509-513.

Nassour, I., Leger, C.L. 1989. Deposition and mobilization of body fat during sexual maturation in female trout (Salmo gairdneri Richardson). Aquaculture Living Resources. 2:153-159.

Nelson, D.L., Cox., M.M. 2013. Lehninger Principles of Biochemistry. 6th ed. W.H. Freeman and CompanyNew York, NY.

Piferrer, F., Beaumont, A., Falguière, J. C., Flajšhans, M., Haffray, P., \& Colombo, L. 2009. Polyploid fish and shellfish: production, biology and applications to aquaculture for performance improvement and genetic containment. Aquaculture, 293(3), 125-156.

Ringø, E. I. N. A. R., Andreassen, T. V., \& Burkow, I. C. 1990. Effects of starvation on the lipid composition in muscle tissue and liver of hatchery-reared Arctic charr, Salvelinus alpinus (L), from lake Takvatn. Fiskeridirektoratets Skrifter. Serie Erncering, 3(2), 13-20.

Salem, M., Kenney, P. B., Rexroad, C. E., \& Yao, J. (2006). Molecular characterization of muscle atrophy and proteolysis associated with spawning in rainbow trout. Comparative Biochemistry and Physiology Part D: Genomics and Proteomics, 1(2), 227-237.

Sheridan, M. A., \& Kao, Y. H. 1998. Regulation of metamorphosis-associated changes in the lipid metabolism of selected vertebrates. American Zoologist, 38(2), 350-368. 
Solar, I. I., Donaldson, E. M., \& Hunter, G. A. 1984. Induction of triploidy in rainbow trout (Salmo gairdneri Richardson) by heat shock, and investigation of early growth. Aquaculture, 42(1), 57-67.

Staver, M. M., Jerković, I., Giacometti, J., Malenica, A., \& Marijanović, Z. 2012. Fatty-Acid Profile of Total and Polar Lipids in Cultured Rainbow Trout (Oncorhynchus mykiss) Raised in Freshwater and Seawater (Croatia) Determined by Transmethylation Method. Chemistry \& biodiversity, 9(8), 1591-1598.

Thorgaard, G.H. 1986. Ploidy manipulation and performance. Aquaculture 57:57-64

Tiwary, B. K., Kirubagaran, R., \& Ray, A. K. 2004. The biology of triploid fish. Reviews in Fish Biology and Fisheries, 14(4), 391-402.

Tocher, D. R. 1995. Glycerophospholipid metabolism. Biochemistry and Molecular Biology of Fishes, 4, 119-157.

Tocher, D. R. 2003. Metabolism and functions of lipids and fatty acids in teleost fish. Reviews in Fisheries Science, 11(2), 107-184.

Tocher, D. R., Bendiksen, E. Å., Campbell, P. J., \& Bell, J. G. 2008. The role of phospholipids in nutrition and metabolism of teleost fish. Aquaculture, 280(1), 21-34.

Voet, D., \& Voet, J. G. 2004. Biochemistry. Hoboken. John Wiley \& Sons, 1, 591

von Wettstein-Knowles, P., Olsen, J. G., McGuire, K. A., \& Henriksen, A. (2006). Fatty acid synthesis. FEBS Journal, 273(4), 695-710.

Watanabe, T., Sugii, K., Saito, H., Okazaki, E. and Yamada, J. 1988 Properties of lipids at development ofcultured triploid ayu. Bulletin Tokai Reg. Fisheries Research Laboratory/Tokaisuikenho 126, 49-59.

Werner, C.A R.S.T.E.N., et al. 2008 "Flesh characteristics of pan-size triploid and diploid rainbow trout (Oncorhynchus mykiss) reared in a commercial fish farm." ARCHIV FUR TIERZUCHT 51.1: 71.

Wood, J.D., Richarson, R.I., Nute, G.R., Fisher, A.V., Campo, M.M., Kasapidou, E., Sheard, P.R., Enser, M.. 2003. Effects of fatty acids on meat quality: a review. Meat Science. 66, 21-32.

Weber, G. M., Hostuttler, M. A., Cleveland, B. M., \& Leeds, T. D. 2014. Growth performance comparison of intercross-triploid, induced triploid, and diploid rainbow trout. Aquaculture, 433, 85-93.

Weil, C., Lefèvre, F., \& Bugeon, J. 2013. Characteristics and metabolism of different adipose tissues in fish. Reviews in Fish Biology and Fisheries, 23(2), 157-173. 
Yamaguchi, T., Omatsu, N., Morimoto, E., Nakashima, H., Ueno, K., Tanaka, T., ... \& Osumi, T. 2007. CGI-58 facilitates lipolysis on lipid droplets but is not involved in the vesiculation of lipid droplets caused by hormonal stimulation. Journal of lipid research, 48(5), 1078-1089. 


\section{INTRODUCTION}

Fish are an important food source for humans as fish are a low-fat, high-protein choice. To meet consumer demand, producers are constantly looking for ways to improve production. Traditionally, optimal fish growth and fillet quality has been limited by sexual maturation. When diploid females mature, they mobilize stored lipids for energy during egg development (Tocher, 2003), compromising the amount and quality of muscle produced. Unlike diploids triploid females are sterile which extends the endpoint of productive growth and do not mobilize nutrients for egg production.

In the aquaculture industry, there are primarily two methods for producing triploid offspring. One way to produce triploid offspring is by introducing eggs to an external shock; thermal and pressure shock are the most common approaches. For this study, we considered triploids that were induced by pressure shock (3NP). For the pressure shock procedure, $9000 \mathrm{psi}$ was applied to eggs for 8 minutes, 30 minutes post-fertilization (Hershberger et al., 2005). Pressure shock induces retention of the second polar body during meiosis II. This is a welldocumented and proven method, often achieving 100\% success. However, Weber et al. (2014), found that triploids produced by pressure had a higher rate of deformities than diploids and triploids produced by crossing. Deformities and abnormalities can be problematic for producers when harvesting fish; variation in shape and conformation affect compatibility with mechanical filleting devices. To avoid the deformities that occur in pressure-induced triploids during early development, a second method of triploid production can be used that crosses a tertaploid (4N) parent with a diploid $(2 \mathrm{~N})$ parent resulting in $100 \%$ triploid offspring. Triploids produced by the crossing of the diploid parent and the tetraploid parent are known as (3NC). Albeit, the tetraploid parent is difficult to achieve because 9000 psi must be applied to the eggs starting at 
$62-65 \%$ of the first cleavage interval (Hershberger et al., 2007). Horstgen-Schwark (1993), reported that the crossing production method yielded low hatch and survival rates, limiting brood stock.

Lee et al. (1989) determined that triploid common grass carp had higher levels of triglycerides than diploids during spawning season. Tocher (2003) established that fatty acid catabolism is the primary source of energy for many fish species. Fish mobilize lipids during periods of high energy demand, potentially compromising fillet quality. In terms of fillet quality, the amount and type of lipid in muscle contribute to the nutritive value and palatability of this muscle food. Triploid, amago Oncorhynchus masou ishikawae had three times the amount of fillet lipid compared to diploids of the same age, during sexual maturation (Saito et al., 1996). During maturation, lipids are mobilized for the production of oocytes. During egg production, vitellogenesis, diploids mobilize unsaturated fatty acids; they catabolize C20:5n-3 (EPA) and transfer C22:6n-3 to the eggs (Tocher, 2003). Long chain, highly unsaturated fatty acids add fluidity and permeability to the oocyte membrane (Purves et al., 2003).

With limited knowledge of fatty acid mobilization and the effect of this process on fillet quality, research is needed. Specifically, there is limited research addressing the relationship between the major lipid classes, primarily triglyceride and phospholipids, and specific differences in sterile triploid fish and fertile diploid fish during maturation. Consequently, this research might aid in development of techniques to optimize production of triploid fish for aquaculture. Weber et al. (2014) found that considering these same fish, triploid 3NC grew as well if not better than diploids and 3NP counterparts. The $3 \mathrm{NC}$ also had a lower number of deformities than the $3 \mathrm{NP}$. 
The primary objective of this investigation is to determine the differences in lipid classes between triploids produced by pressure (3NP), and triploids produced by crossing (3NC). Specifically, comparing fatty acid profiles to establish possible differences between the triglyceride, and the phospholipid lipid classes within the two different triploid groups, and compared to the diploid females. Additionally, separable muscle yield, fillet yield, texture, and proximate composition data will also be considered to characterize differences in fillet attributes as affected by ploidy and method of ploidy induction. 


\section{MATERIALS AND METHODS}

\section{$\underline{\text { Experimental Design }}$}

Fish care and experimentation followed guidelines outlined by the US Department of Agriculture (USDA) and the National Center for Cool and Cold Water Aquaculture (NCCCWA; USDA Agricultural Research Service; Kearneysville, WV, U.S.A.) Animal Care and Use Committee; these guidelines are in line with the National Research Council publication Guide for Care and Use of Laboratory Animals. Triploid production and experimental protocol, including experimental design, are reported in Weber et al. (2014). Eggs came from a common female and were randomly assigned to each of the three ploidy treatments, $2 \mathrm{~N}, 3 \mathrm{NC}$, and $3 \mathrm{NP}$. This would make $2 \mathrm{~N}$ and $3 \mathrm{NP}$ full siblings, while $3 \mathrm{NC}$ would be considered $3 / 4$-siblings because the tetraploid $(4 \mathrm{~N})$ male that fertilized the egg was a sibling to the $2 \mathrm{~N}$ male that fertilized the $2 \mathrm{~N}$ and 3NC. Fish were comingled in triplicate $830 \mathrm{~L}$ tanks after PIT tags were implanted at 26 weeks post hatching. At week 53 post hatching, fish were moved to $2400-\mathrm{L}$ tanks and, to maintain appropriate densities fish were moved to $4270 \mathrm{~L}$ tanks at 66 weeks for the remainder of the study. Fish were fed a commercial fish meal diet (42\% protein, $16 \%$ fat, $2 \%$ fiber; Zeigler Brothers, Inc.; Gardners, PA,U.S.A.) that was dispensed by belt feeders (Arvotec; Huutokoski, Finland). Daily feeding was $2.5 \%$ whole body weight at tagging which decreased as fish grew; $1 \%$ by week $64,0.75 \%$ by week 72 , and $0.5 \%$ from week 76 to the remainder of the study.

\section{$\underline{\text { Sample Collection }}$}

Fish weights and lengths were recorded every 4 weeks, starting at 26 weeks post hatching: these monthly growth measurements were reported by Weber et al. (2014). In February at week 94, fish were harvested using an overdose of tricaine methanesulfonate (MS- 
222, Western Chemicals, Ferndale, CA, U.S.A.) at $300 \mathrm{mg} / \mathrm{L}$. At this time, a subset of fish was processed to recorded whole body weight (WBW), fork length, and percent separable muscle. Additionally, proximate composition, cook yield and texture of boneless, skinless, fillets was determined. Separable muscle yield is boneless, skinless fillet weight expressed as a percent of whole body weight; and butterfly fillet is the skin-on fillet with viscera, vertebrae and ribs removed.

\section{$\underline{\text { Texture Analysis }}$}

Texture analysis was done on $8 \times 4 \mathrm{~cm}$ fillet sections that were taken from musculature centered on the lateral line, 2-3-cm caudal to the pectoral girdle of the right fillet. Sections were thermally processed in a micro-processor-controlled smoke oven (Model CVU-490;Enviro-Pak, Clackamas, OR, USA) at $82{ }^{\circ} \mathrm{C}$, and the cooking process was stopped when the internal temperature reached $65.5^{\circ} \mathrm{C}$. This cooking temperature was selected according to the USDA recommended, minimum internal temperature for fish to achieve a safe temperature without overcooking (Nilsson and Ek-strand 1995). Total cooking time was approximately 45 min. After cooking, product was allowed to cool to room temperature. Cook loss was calculated as [100 (cook weight/raw weight X 100)]. Instrumental texture was measured using a 5-blade, AlloKramer shear attachment mounted to the TA-HDi® Texture Analyzer (Texture Technologies Corporation; Scarsdale,NY,USA), a 50-kg load cell was used and tests were performed at a crosshead speed of $127 \mathrm{~mm} / \mathrm{min}$. Shear force was applied perpendicular to the muscle fiber orientation. Force deformation graphs were recorded, and average peak force (peak force/g of sample) and total energy of shear $(\mathrm{g} / \mathrm{mm})$ were determined using the Texture Expert Exceed software (version 2.60; Stable Micro Systems Ltd., Surrey, UK). 


\section{$\underline{\text { Sample Processing }}$}

To prepare samples for compositional and fatty acid analyses, frozen fillets were tempered and ground while partially frozen using a Kessel table top meat grinder (Model MFR. 28447; Kitchen Equipment Co., INC.; Lawrence TWP, New Jersey, U.S.A.). A random sample of the ground material was collected, frozen in liquid nitrogen, and powdered in a stainless-steel, Waring commercial blender (Model 51BL31; Waring Commercial; Torrington, Connecticut, U.S.A.). A subsample of the powdered sample was stored at $-80^{\circ} \mathrm{C}$ until fatty acid analysis. The remainder of the powdered sample was stored at $-20^{\circ} \mathrm{C}$ until proximate composition analyses.

\section{$\underline{\text { Proximate Analysis }}$}

For proximate analysis; all procedures followed AOAC approved methods (AOAC, 1990). Moisture, crude fat, crude protein, and ash content was determined for muscle samples. In Each measurement was performed in duplicate and expressed as an average of duplicate measurements. Percent moisture was determined by drying approximately one gram of sample overnight at $110^{\circ} \mathrm{C}$ in a Stabil-Therm Gravity Oven (Blue-M Electric Company; Blue Island, Illinois, U.S.A.). Moisture loss was calculated as a percent of the sample. Percent crude fat was determined for muscle, liver, and visceral fat based on the difference before and after extraction with petroleum ether. One gram samples were wrapped in Whatman 41 filter paper, and fat was extracted in a Soxhlet extractor for at least eighteen hours. Following extraction, samples were dried overnight at $110^{\circ} \mathrm{C}$ and reweighed. Percent crude fat of the gonads was estimated by difference using moisture, ash, and crude protein content. Ash content was measured by ashing a one gram sample in a crucible at $550^{\circ} \mathrm{C}$ overnight in a type $\mathrm{A} 1500$ furnace (F-A1525M-1; Thermolyne Corporation; Dubuque, Iwoa, U.S.A.). The difference in weight between initial and 
ashed sample was used to calculate percent ash. Crude protein was determined using Kjeldahl N determined by the Kjeltec $^{\mathrm{TM}} 2300$ (Foss North America; Eden Prairie, Minnesota, U.S.A.). Half gram samples and copper-sulfate tablets, used as a catalyst, were dissolved in $10 \mathrm{~mL}$ of sulfuric acid $\left(\mathrm{H}_{2} \mathrm{SO}_{4}\right)$. Samples were heated in a $400^{\circ} \mathrm{C}$ heating block, equipped with an exhaust manifold for approximately $1.5 \mathrm{~h}$ to accomplish digestion. After cooling, $25 \mathrm{~mL}$ of distilled water was added with swirling and heating to re-suspend solids. Tubes containing the solutions were distilled on the Kjeldal machine for titration. Milliliters of acid required to titrate the sample was then used to determine nitrogen content and thereby calculate percent crude protein using 6.25 as the conversion factor (Appendix 2).

\section{$\underline{\text { Fatty Acid Analyses }}$}

Lipid Extraction. Total lipids were extracted according to Bligh and Dyer (1959) using a chloroform-methanol (C:M) mixture (2:1 v/v) (Appendix 10). A 1.0 gram of sample was used for fatty acid analysis. Buffer (50mM Trizma/EDTA, $\mathrm{pH}=7.4)$ and solvent (chloroform: absolute methanol: glacial acetic acid (C:M:A); 400:200:3mL) were added with sample and the mixture was incubated at room temperature for 10 minutes; the mixture was centrifuged at 900x g (4000 $\mathrm{rpm}$ ) for 10 minutes at $10{ }^{\circ} \mathrm{C}$. The resulting lower layer was filtered through a 1-PS filter that had been rinsed with 2:1, C:M. The upper layer was again extracted and separated by centrifugation with 4:1, C:M. The resulting lower layer was filtered through a 1-PS filter. The combined filtrates for each sample were dried with nitrogen gas at $60{ }^{\circ} \mathrm{C}$.

Methylation. Fatty acids were methylated using the method described by Fritshe and Johnston (1990). Four percent $\mathrm{H}_{2} \mathrm{SO}_{4}$, in anhydrous methanol, was added to the extracted lipid 
sample and incubated at $90{ }^{\circ} \mathrm{C}$ for 60 minutes. The reaction was stopped by cooling to room temperature and adding $3 \mathrm{~mL}$ deionized water. This sample mixture was extracted with $8 \mathrm{~mL}$ chloroform and centrifuged at $900 \mathrm{x}$ g at $10{ }^{\circ} \mathrm{C}$ for 10 minutes. The bottom chloroform layer, containing the fatty acid methyl esters (FAME), was filtered through a $\mathrm{Na}_{2} \mathrm{SO}_{4}$ filled pipette into a $10 \mathrm{~mL}$ glass tube. The pipette was rinsed with chloroform. The extract was dried with nitrogen gas at $60{ }^{\circ} \mathrm{C}$ and the dried sample was re-suspended in $3 \mathrm{~mL}$ of filtered isooctane and stored at $20{ }^{\circ} \mathrm{C}$ until further analysis.

Fatty Acid Separation and Quantification. Nonadecanoic (19:0) acid was used as an internal standard added prior to methylation. Fatty acid methyl esters were quantified using a Varian CP-3800 Gas Chromatograph (Varian Analytical Instruments; Walnut Creek, California, U.S.A.) equipped with a flame ionization detector (FID; Varian Inc., Walnut Creek, California, U.S.A). A WCOT, fused silica capillary column (100-m length, 0.25-mm inside diameter; Varian Inc., Walnut Creek, California, U.S.A.) was used to separate fatty acid methyl esters. The stationary phase was CP-Sil 88 for FAME, with nitrogen as a carrier gas at a flow of $0.3 \mathrm{~mL} / \mathrm{min}$. A 10-to-1 split ratio was applied for all sample analyses. A temperature program of $140{ }^{\circ} \mathrm{C}$ for 5 minutes followed by a temperature ramp of $3{ }^{\circ} \mathrm{C} / \mathrm{min}$ to $235^{\circ} \mathrm{C}$ was adopted; this temperature was held for 15 minutes. The total time for each sample separation was 68.5 minutes. The injector (11-77 injector, Varian Inc., Walnut Creek, California, U.S.A.) and detector temperatures were maintained at 270 and $300^{\circ} \mathrm{C}$, respectively.

Fatty acid methyl esters were identified based on comparison to the retention times of standard fatty acid methyl esters (SupelcoTM quantitative standard FAME 37; Sigma-Aldrich, 
St. Louis, Missouri, U.S.A.). Peak area and the relative amount of each fatty acid were computed by an integrator using the Star GC workstation version 6 software (Varian Inc., Walnut Creek, California, U.S.A.).

\section{Thin Layer Chromatography}

Thin layer chromatography (TLC) was applied to separate fatty acid lipid classes. Lipid was extracted from one gram of muscle sample following the Bligh and Dyer (1959) extraction protocol previously described. Once extracted, $7 \mu 1$ of oil was added to a small vial containing $12 \mu \mathrm{l}$ of 1:1 chloroform:methanol to facilitate plating. The $19 \mu \mathrm{l}$ volume was then pipetted onto the TLC plate (Whatman K5F silica gel plates with 150A pore size, P.J. Cobert Associates, ST. Louis, MO), approximately 1 inch from the bottom of the plate. The TLC plate was developed using an 80:20:1.5, hexane:ether:glacial acetic acid mixture (v:v:v) as the mobile phase.

Following development for approximately an hour, or until solution was 1 inch from the top of the plate, the plate was removed to air dry for 5 minutes.

The plate was then exposed to a black light to visualize the various lipid classes. Phospholipids and triglycerides were identified, respectively, using known retention factor $\left(\mathrm{R}_{\mathrm{F}}\right)$ values determined by running sphingomyelin (Sigma-Aldrich, St. Louis MO) and a mono, di, and triglyceride mixture (Supelco, Bellefonte, PA). The identified area of the stationary phase was scraped into a $35 \mathrm{~mL}$ test tube where $100 \mu \mathrm{L}$ of internal standard was added before fatty acid methylation was conducted on the sample. After methylation, the sample was re-suspended in $1.5 \mathrm{~mL}$ of filtered isooctane and stored at $-20^{\circ} \mathrm{C}$ until further analysis. 


\section{$\underline{\text { Statistical analysis }}$}

In context of a completely randomized design the independent variable was ploidy $(2 \mathrm{~N}$, 3NP, 3NC) with fish as the experimental unit. Production of experimental animals in full can be found in Weber et al. (2014). Eggs from a common female were randomly assigned to each of 3 ploidy treatments, 2N, 3NP and 3NC. Our 86 fish represented, a February 94 week old single time-point, of a larger growth study conducted by Weber et al. (2014). Each ploidy was represented by12 fish giving a total of 36 fish that were randomly selected from a lot of 86 at harvest. Harvested whole body weight, fork length, separable muscle, butterfly fillet, cook yield, texture, proximate composition (moisture, crude fat, crude protein, ash), and total fatty acid profile was analyzed using analysis of variance to test for main effects of ploidy (PROC GLM SAS Version 9.1; 2004). Ploidy was considered as individuals with 12 fish representing the 3 ploidies to give 36 individuals. Effects were considered significant at $\mathrm{P} \leq 0.05$. Data are presented at LSMeans \pm SEM (standard error of the mean).

Triglycerides and phospholipids were analyzed within each individual. Lipid classes were analyzed using analysis of variance to test for main effects of ploidy within each lipid class, by the general linear models procedure (SAS Version 9.1; 2004). Effects were considered significant at $\mathrm{P}<0.05$. Fatty acids within lipid classes are presented as relative peak area with LSMeans \pm SEM. 


\section{RESULTS AND DISCUSSION}

\section{Carcass Yield}

Carcass yield data is represented in table 1 . Whole body weight was heaviest in $3 \mathrm{NC}$ and lightest in $3 \mathrm{NP}(\mathrm{P}<0.05)$. However, $2 \mathrm{~N}$ weights were intermediate, but not different $(\mathrm{P}>0.05)$ from $3 \mathrm{~N}$ treatments. This study used a subsample of fish collected from the study reported by Weber et al. (2014); for this reason, our analysis supports their conclusion that $3 \mathrm{NC}$ fish were the heaviest followed by $2 \mathrm{~N}$ and $3 \mathrm{NP}$ individuals. Chourrout et al. (1986) reported that $3 \mathrm{NC}$ and $2 \mathrm{~N}$ body weights exceeded those of 3NPs, which were produced by heat shock, when fish were reared to approximately $50 \mathrm{~g}$. Our data is consistent with those of Weber et al. (2014) who found that $3 \mathrm{NC}$ were longer compared to the $3 \mathrm{NP}$, but we found no significant difference in length between $2 \mathrm{~N}$ and $3 \mathrm{NC}$ females. However, $2 \mathrm{~N}$ and $3 \mathrm{NC}$ were longer $(\mathrm{P}<0.05)$ than $3 \mathrm{NP}$ fish. Weber et al. (2014) reported that 3NP individuals had the lowest condition factor of all ploidies. A higher condition factor is often associated with greater fillet yields. Our data did not support this relationship. From a production stand point, the most important characteristic is muscle yield. Separable muscle is a direct indication of muscle mass because it is the boneless skinless fillet harvested from the fish. Considering separable muscle on a weight basis and as expected, $3 \mathrm{NC}$ and $2 \mathrm{~N}$ fillets were larger than $3 \mathrm{NP}$; however, when expressed as a percent of whole body weight, 3NC was greater than 3NP yields and both ploidies were 8.2 and $5.3 \%$ greater, respectively, than $2 \mathrm{~N}$ yields. A study of rainbow trout on a low plane of nutrition indicated triploids had $11 \%$ more separable muscle compared to diploids because diploids were catabolizing muscle to support gonadogenesis (Salem et al. 2006). Butterfly fillet is a trout product similar to boneless, skinless fillets (separable muscle); however, it has not yet had the trim (operculum collar, skin, pectoral fins, and belly flap) removed. Butterfly fillet weights for $3 \mathrm{NC}$ fish were heavier than for $2 \mathrm{~N}$ and $3 \mathrm{NP}$ fish, and these ploidies were not different $(\mathrm{P}>0.05)$. 
However, butterfly fillet as a percent of whole body weight, showed that muscle yield of 3NC individuals was greater than yields of $3 \mathrm{NP}$ and $2 \mathrm{~N}$ fish; $2 \mathrm{~N}$ fish were the lowest yielding $(\mathrm{P}<0.05)$.

\section{$\underline{\text { Cook Yield \& Texture }}$}

Cook yield and texture were not affected $(\mathrm{P}>0.05)$ by ploidy. Albeit, a trend in our data indicates that $3 \mathrm{NC}$ fillets required less force $(\mathrm{g} / \mathrm{g})$ to shear than $2 \mathrm{~N}$ and $3 \mathrm{NP}$ fillets. Aussanasuwannakul et al. (2011) reported that diploid fillets required more force to shear than triploid fillets. It appears that intramuscular fat played a role in influencing fillet texture. Increased intramuscular fat content in rainbow trout is associated with hypertrophic growth of muscle fibers (Fauconneau et al., 1997). Muscle that contains higher fat content tends to be more tender, while lean specie tenderness is increased by water content. Many factors influence cook yield of rainbow trout fillets (Werner et al. 2008). Numerically, 3NC fillets exhibited the highest cook yield followed by the $3 \mathrm{NP}$ and the $2 \mathrm{~N}$ fillets. This response could be influenced by moisture content and water holding capacity differences for the muscle of these ploidies. Water holding capacities may be affected by muscle fiber size, with triploids (3NC, 3NP) having larger muscle fibers compared to diploids (2N) (Pootawee et al., 2007). Animals with larger muscle fibers are generally more susceptible to stress. Prior to slaughter, animals with larger, anaerobic muscle fibers are not able to compensate for stress related adjustments to metabolism; specifically these animals may have increased anaerobic glycolysis and lactic acidosis thus reducing muscle $\mathrm{pH}$ (Werner et al. 2008). Our data does not support this idea that triploids are more susceptible to stress-related acidosis, predisposing them to a reduced water holding capacity. This decreased cook yield in the $2 \mathrm{~N}$ fillets may be associated with higher moisture and lower intramuscular crude fat content. Muscles with higher intramuscular fat content tend to 
have higher water holding capacities (Lawrie 1991). Cook yield will be influenced by heating rate that would, in turn, be influenced by fillet thickness, which we did not measure, and intramuscular fat. Mangalassary et al. (2004) found that meat that was thicker and with higher fat content had a decreased rate of heating. That would explain the greater cook loss in $2 \mathrm{~N}$ because they had lower fat content and we could conclude thinner fillets compared to other ploidies. Not only do these factors influence cook yield, they also influence texture because the balance of protein-water, protein-protein, and protein-fat is influenced by heating rate.

\section{Fillet Proximate Composition}

Moisture content is an indication of a more advanced state of maturity; moisture content is inversely related to fat content because this component is consumed for energy during spawning (Gilhousen, 1980; Hendry and Berg 1999). Moisture content was highest for 2N fillets followed by $3 \mathrm{NP}$ and $3 \mathrm{NC}$ fillets (Table $1 ; \mathrm{P}<0.05$ ). Our composition data are consistent with those reported by Aussanasuwannakul et al. (2011); intramuscular moisture of diploids (2N) was approximately $73 \%$ compared to $67 \%$ for triploids that were generated using pressure. Salem et al. (2006) reported that fish fed on a low plane of nutrition had much higher intramuscular moisture content than triploids, 81 versus $77 \%$, respectively. This observation would support the assertions that these $2 \mathrm{~N}$ fertile fish used lipid and protein stored within the fillet to support egg development. As previously stated, crude fat content is inversely related to moisture content, with $3 \mathrm{NC}$ fillets containing the greatest amount of crude fat followed by $3 \mathrm{NP}$ and $2 \mathrm{~N}$ fillets that had the least intramuscular crude fat content (Table 1, $\mathrm{P}<0.05)$.

From a consumer standpoint, excessive crude fat can alter palatability of the product. In terrestrial animals, intramuscular fat content at a level of 3 to $7.3 \%$ contributes positively to 
sensory texture (Smith et al., 2004). Taking that into consideration, all ploidies had crude fat contents above that range. At higher fat levels, marbling imbedded in the perimyseal connective tissue can undermine mechanical strength of connective tissue (Miller, 2004). Crude fat level within the fillet is depleted as diploids progress through gonadal development (Aussanasuwannakul et al., 2011). Crude fat in the fillet is preferentially used before crude protein. As Salem et al. (2006) showed, fish on a low plane of nutrition had minimal stores of intramuscular fat $2.6 \%, 3 \%(2 \mathrm{~N}, 3 \mathrm{~N}$ respectively). As a result, these females mobilized crude protein stores for energy, observed as severe atrophy of the muscle and decreases in percent separable muscle. Furthermore, they saw a significant difference decrease crude protein content of diploids compared to triploids, with diploid mobilizing more crude protein to support egg development. In this study our fish were fed a high plane of nutrition; therefore stress imposed by egg growth and development was not sufficient enough to cause protein catabolism; therefore, we did not see a significant effect of ploidy on crude protein content. Others also reported no significant effect of ploidy on protein content in well fed fish (Poontawee et al., 2007;

Aussanasuwannakul et al., 2011). Lastly, percent ash only varied slightly, with our fish being well within the typical range of ash content. Subtle differences may be associated with subtle differences in pin bone content which we did not remove; nonetheless, 3NP had the highest percent ash and $3 \mathrm{NC}$ had the lowest percent ash.

\section{Fillet Fatty Acid Content}

Relative Peak Area (RPA) Compsrison. Sexual maturation is a dominant homeorethic process that causes fish to alter metabolism to support egg development (Manor et al., 2012). This altered metabolism can influence muscle fatty acid composition, and changes in fatty acid composition are of interest to consumers and producers. Ploidy affected 8 out of the 22 
fatty acids (Table $2 ; \mathrm{P}<0.05)$. In general, triploids $(3 \mathrm{NC}, 3 \mathrm{NP})$ muscle tissue contained more saturated fatty acids (SFA) than $2 \mathrm{~N}$ muscle tissue. Triploids appear to stored more short chain fatty acids such as C12:0, C14:0 and C16:0 and this observation is consistent with Manor et al. (2014). These fish preferentially store fatty acids as shorter chain fatty acids rather than elongate and desaturate them to polyunsaturated fatty acids. Metabolically, triploids do not have as much physiological need for these long chain fatty acids as diploids, and these long chain fatty acids are more difficult to store (Nelson and Cox, 2013). The end product of de novo fatty acid synthesis is $\mathrm{C} 16: 0$, and triploids (3NC, 3NP) appear to stop at that point rather than elongate and desaturate this fatty acid. Our data showed that $2 \mathrm{~N}$ muscle tissue contained more polyunsaturated fatty acids (PUFA) than muscle from triploid females. Ribeiro et al. (2012) suggested that diploids have higher PUFAs compared to triploids due to changes that are occurring in support of reproduction. Because triploids are sterile, they do not spend energy to accumulate these fatty acids for further mobilization to the ovaries during gonadogenesis. Additionally, lower levels of PUFAs in sterile triploid females (3NC and 3NP) could be associated with a dilution of membrane lipids by stored, neutral triglycerides. Diploid muscle tissue contained more $\omega 3$ fatty acids, primarily C22:6n3 (DHA), compared to muscle tissue from 3NC and 3NP females. Docosahexaenoic acid is important in the final process of egg development (Ribeiro et al., 2012). Sorbera et al. (2001) suggested that $\omega 3$ PUFAs and their metabolites participate in the regulation of ovarian steroidogeneisis and these fatty acids are directly involved in the final maturation of fish. This physiological role may suggest that rainbow trout use muscle stores of these PUFAs for later mobilization to the ovaries as part of sexual maturation process. 
Additionally, $2 \mathrm{~N}$ females had the highest concentration of $\omega 6$ fatty acids in their muscle, followed by $3 \mathrm{NP}$ and 3NC females; 3NC tissue, containing the highest level of crude lipid, had the lowest concentration of $\omega 6$ fatty acids. Of the $\omega 6$ fatty acids, C20:4n6, arachidonic acid (ARA), was the most prevalent; this fatty acid is important in yolk composition and it is an eicosanoid precursor involved in steroidogenesis and oocyte maturation in vertebrates (Astuarino et al., 2001). The $\omega 3: \omega 6$ ratio was not affected $(\mathrm{P}>0.05)$ by ploidy. This data is consistent with Manor et al. (2014) who also found no significant difference between diploids and triploids (3NP) for $\omega 3: \omega 6$ ratio. Albeit, Ribeiro et al. (2012) reported that the $\omega 3: \omega 6$ ratio differed between diploids and triploids (heat shock) as the triploids matured, which would suggest these fish might be harvested earlier at a higher $\omega 3: \omega 6$ ratio. Ploidy did not affect $(\mathrm{P}>0.05)$ level of monounsaturated fatty acids (MUFA) in muscle tissue for the current study. Fatty acids calculated on a mg/g basis can be found in appendix 3 .

\section{Lipid Class Fatty Acid Composition}

Triglycerides. Triglycerides are the primary storage form of energy within fish (Tocher, 2003). During times of high energy demand, such as gonadogenisis, fish mobilize these stores to provide fatty acids and energy for egg development. Anatomical location of adipose tissue affects how and when the fatty acids will be used. Rainbow trout preferentially mobilize visceral fat to support gonadogenesis before mobilizing intramuscular fat (Nassour and Leger 1989). These fish were also managed on a relatively high plane of nutrition, and this nutritional regimen might explain why intramuscular fat of $2 \mathrm{~N}$ females did not fall below $8 \%$. Dietary lipid can be processed within the fish and packaged into chylomicrons. When energy is needed, muscle can use chylomicrons without lipolysis of stored fat (Boyer, 2002). Because visceral fat is mobilized before intramuscular lipids and considering the high plane of nutrition, it is not surprising that 
intramuscular lipid were not severely depleted causing no differences in intramuscular triglyceride fatty acid profile.

Muscle tissue from 3NC females contained more $\mathrm{C} 16: 0(\mathrm{P}<0.10)$ than other ploidies, based on relative peak areas (Table 3). Palmitic acid is typically found within the diet (Manor et al., 2012; Manor et al., 2014) at a higher concentration than other fatty acids. Moreover, C16:0 is also the end product of de novo fatty acid synthesis. A greater relative concentration of C16:0 within muscle could be a function of increased feed intake or de novo fatty acid synthesis. Conversely, 3NC tissue contained less C18:3n3 compared to the other ploidies. Ploidy did not $(\mathrm{P}>0.10)$ affect other fatty acids within the triglyceride lipid class. The major fatty acid found in triglycerides was oleic (C18:1n9c) acid. Our results are consistent with those of Castell (1972) that considered whole body lipids and found more oleic acid relative to other fatty acids; oleic acid was preferentially deposited in triglycerides for diets varying in oleic acid.

Phospholipids- Phospholipids' main role is to provide structural integrity to cellular membranes. Fatty acid length and degree of saturation have varying effects on membrane fluidity. Shorter fatty acid chains and more unsaturated fatty acids increase the fluidity of the membrane (Purves et al., 2003). Furthermore, longer, more saturated fatty acids decrease membrane fluidity. Poikilotherms, such as fish, adapt to environmental changes by altering the physical properties of the membrane in order to preserve function and structural integrity; this effect is known as homeoviscous adaptation (Dey et al., 1993). To function properly, organisms under cold conditions incorporate more unsaturated fatty acids into the phospholipid membranes, along with fatty acids with shorter tails. When considering the fatty acid profile of intramuscular phospholipids, our data (Table 4) supports the aforementioned paradigm in that all ploidies had high levels of $\mathrm{C} 16: 0, \mathrm{C} 18: \ln 9 \mathrm{c}$ and $\mathrm{C} 22: 6 \mathrm{n} 3$ in their phosopholipids. These three fatty acids are 
generally the major fatty acids found within cold acclimated fish (Castell et al., 1972; Satar et al., 2012; Buda et al., 1994); and salmonids such as Oncorhynchus mykiss (rainbow trout) which are a cool and cold-water specie.

Ploidy did not affect fatty acid composition within the phospholipid class (Table 5). This response is reasonable because $2 \mathrm{Ns}$ were not exposed to a plane of nutrition where phospholipids would have been used to support maturation. If $2 \mathrm{Ns}$ reached that stage of nutritional insult, they would likely abort egg production or ovulate early to prevent the continued degradation of intramuscular phospholipids (Conteras-Sanchez et al., 1998).

Triglyceride/phospholipid Comparison - As previously discussed, phospholipids within lipid membranes, prefer to have shorter chained fatty acids or fatty acids rich in desaturations. Our data show that phospholipids contained more $(\mathrm{P}<0.05) \mathrm{C} 16, \mathrm{C} 20: 4 \mathrm{n} 6, \mathrm{C} 20: 5 \mathrm{n} 3$ and $\mathrm{C} 22: 6 \mathrm{n} 3$ compared to triglycerides (Table 5). Salze et al. (2005) determined that highly unsaturated fatty acids such as 20:5n3, 22:6n3 and 20:4n6 impact egg quality in cod. Of those, they determined that C20:4n6, arachidonic acid (ARA), was the largest contributor to egg quality. Our data indicated that these fish stored 7 times more $\mathrm{C} 20: 4 \mathrm{n} 6$ in phospholipids than in triglycerides. Arachidonic acid, an n-6 PUFA, is known to have pro-inflammatory and immunoactive functions on eicosanoids that include prostaglandins, thromboxanes, and leukotrienes (Wall et al., 2010; Bell et al., 1995). Whereas, eicosanoids derived from n-3 PUFAs such as DHA (C22:6n3) and EPA (C20:5n3) have anti-inflammatory properties, attributed to their ability to block n-6 PUFA eicosanoid formation (Calder et al., 2010). Docosahexaenoic acid (DHA) was present in phospholipids at three times the level observed for triglycerides. This difference is expected because DHA is important to maintaining the structure of cell membranes (Yanes-Roca et al., 2009). Also, phospholipids had twice as much EPA as triglycerides. Conversely, triglycerides 
contained more $(\mathrm{P}<0.05) \mathrm{C} 16: 1 \mathrm{C} 18: 1 \mathrm{n} 9, \mathrm{C} 18: 2 \mathrm{n} 6 \mathrm{c}, \mathrm{C} 18: 3 \mathrm{n} 3$, and $\mathrm{C} 22: 1 \mathrm{n} 9$. All vertebrates including fish, lack $\Delta 12$ and $\Delta 15$ desaturases and cannot form 18:2n6 and 18:3n3 from 18:1n9 (Tocher 2003). This data suggests that dietary essential fatty acids18:2n6 and 18:3n3 were preferentially deposited within the triglyceride class. Tocher (2003) indicated that the pathway is now understood for synthesis of 20:5n3 and 22:6n 3 from 18:3n3 in rainbow trout. This pathway might explain why phospholipids have higher $20: 5 \mathrm{n} 3$ and $22: 6 \mathrm{n} 3$ and lower $18: 3 \mathrm{n} 3$ because the longer chain fatty acids are key for membrane fluidity. Myrisitic (C14:0), stearic (C18:0), and eicosadienoic (C20:2) acids were not different $(\mathrm{P}>0.05)$ between lipid classes.

\section{Conclusion and Summary}

Method of ploidy induction significantly influences carcass traits; however, ploidy induction method has little influence on intramuscular fatty acid composition. Triploids produced by natural matings ( $4 \mathrm{~N}$ males $\mathrm{X} 2 \mathrm{~N}$ females; $3 \mathrm{NC}$ ) had larger fillets compared to triploids generated by pressure (3NP). There were minimal differences seen in muscle fatty acid composition between $3 \mathrm{NP}$ and $3 \mathrm{NC}$ females. Diploid $(2 \mathrm{~N})$ rainbow trout undergo metabolic reprogramming that alters lipid partitioning in support of gonadal development. Nonetheless, these effects were not pronounced in muscle when fish are on a high plane of nutrition. The fatty acid profiles of intramuscular triglycerides and phospholipids are not affected by ploidy. A comparison of triglyceride to phospholipid classes revealed a higher accumulation of C22:6n3 (DHA) within phospholipids.

This information will aid producers in identifying optimum harvest endpoints based on ploidy and ploidy induction method. Producers rearing diploid ( $2 \mathrm{~N})$ fish, may consider harvesting sooner when separable muscle percent and muscle quality would be higher before 
they undergo the deteriorating effects of gonadogenisis. Triploids $(3 \mathrm{~N})$, however can be grown to a larger size but producers should also consider at what point do they shift from producing separable muscle to crude fat to the point that accumulation of fat alters palatability. 
TABLES

\begin{tabular}{|c|c|c|c|c|c|}
\hline & $2 \mathrm{~N}$ & $3 N C$ & $3 \mathrm{NP}$ & P-values & LSMean Error \\
\hline WBW (g) & $1826.3^{\mathrm{ab}}$ & $2109.2^{\mathrm{b}}$ & $1524.2^{\mathrm{a}}$ & 0.0019 & 106.2 \\
\hline $\begin{array}{l}\text { Separable } \\
\text { Muscle (g) }\end{array}$ & $706.2^{\mathrm{b}}$ & $984.0^{\mathrm{b}}$ & $665.8^{\mathrm{a}}$ & 0.0002 & 51.7 \\
\hline $\begin{array}{l}\text { Separable } \\
\text { Muscle (\%) }\end{array}$ & $38.3^{\mathrm{a}}$ & $46.5^{\mathrm{c}}$ & $43.6^{\mathrm{b}}$ & $<0.0001$ & 0.7 \\
\hline $\begin{array}{l}\text { Butterfly } \\
\text { Fillet (g) }\end{array}$ & $1043.9^{\mathrm{a}}$ & $1412.5^{\mathrm{b}}$ & $971.5^{\mathrm{a}}$ & 0.0001 & 69.1 \\
\hline $\begin{array}{l}\text { Butterfly } \\
\text { Fillet }(\%)\end{array}$ & $57.0^{\mathrm{a}}$ & $67.0^{\mathrm{c}}$ & $63.8^{\mathrm{b}}$ & $<0.0001$ & 0.8 \\
\hline $\begin{array}{l}\text { Length } \\
(\mathbf{m m})\end{array}$ & $472.0^{\mathrm{b}}$ & $498.8^{b}$ & $439.3^{\mathrm{a}}$ & 0.0014 & 10.5 \\
\hline Cook Yield & 84.7 & 85.8 & 84.9 & 0.4192 & 0.6 \\
\hline Texture & 21989.3 & 22632.0 & 23603.4 & 0.9186 & 2785.0 \\
\hline $\begin{array}{l}\text { Shear force } \\
(g / g)\end{array}$ & 334.4 & 274.1 & 347.4 & 0.2812 & 34.1 \\
\hline \multicolumn{6}{|l|}{$\begin{array}{l}\text { Muscle } \\
\text { Composition }\end{array}$} \\
\hline $\begin{array}{l}\text { Moisture } \\
(\%)\end{array}$ & $72.3^{\mathrm{c}}$ & $66.7^{\mathrm{a}}$ & $68.8^{\mathrm{b}}$ & $<0.0001$ & 0.6 \\
\hline $\begin{array}{l}\text { Crude Fat } \\
(\%)\end{array}$ & $8.2^{\mathrm{a}}$ & $13.4^{\mathrm{c}}$ & $11.2^{\mathrm{b}}$ & $<0.0001$ & 0.6 \\
\hline $\operatorname{Ash}(\%)$ & $1.2^{\mathrm{ab}}$ & $1.1^{\mathrm{a}}$ & $1.3^{\mathrm{b}}$ & 0.0219 & 0.04 \\
\hline $\begin{array}{l}\text { Crude } \\
\text { Protein }\end{array}$ & 19.4 & 19.5 & 20.0 & 0.1005 & 0.02 \\
\hline $\mathbf{N}$ & 12 & 12 & 12 & & \\
\hline
\end{tabular}

Table 1: EFFECTS OF PLOIDY ON CARCASS YIELD AND PROXIMATE COMPOSITION

LSMean \pm SEM for whole body weight (WBW), percent separable muscle, butterfly fillet, fork length, and proximate compositions. Separable muscle was calculated by representing the boneless-skinless fillet weight as a percent of WBW. Moisture, crude fat and ash contents of epaxial muscle were measured using AOAC approved methods (AOAC, 2000). Superscripts indicate effects of ploidy. Means with the same letters are not significantly difference ( $p>0.05)$. 


\begin{tabular}{|c|c|c|c|c|c|}
\hline Fatty acid & $2 \mathrm{~N}$ & $3 \mathrm{NC}$ & $3 \mathrm{NP}$ & P-value & $\begin{array}{l}\text { LSMean } \\
\text { Error }\end{array}$ \\
\hline C12:0 & $0.02^{\mathrm{a}}$ & $0.05^{b}$ & $0.05^{b}$ & $<0.0001$ & 0.0004 \\
\hline C14:0 & $3.41^{\mathrm{a}}$ & $4.45^{\mathrm{b}}$ & $4.43^{b}$ & $<0.0001$ & 0.11 \\
\hline C15:0 & 0.22 & 0.24 & 0.26 & 0.4942 & 0.03 \\
\hline C16:0 & $21.10^{\mathrm{a}}$ & $25.73^{c}$ & $24.03^{b}$ & $<0.0001$ & 0.33 \\
\hline C16:1 & $8.02^{\mathrm{a}}$ & $9.66^{\mathrm{c}}$ & $8.83^{b}$ & $<0.0001$ & 0.20 \\
\hline C17:0 & 0.22 & 0.21 & 0.23 & 0.1476 & 0.008 \\
\hline C17:1 & 0.21 & 0.18 & 0.18 & 0.4103 & 0.02 \\
\hline C18:0 & 4.33 & 4.27 & 4.42 & 0.285 & 0.06 \\
\hline C18:1n9t & 0.15 & 0.10 & 0.13 & 0.2583 & 0.02 \\
\hline C18:1n9c & $27.86^{\mathrm{b}}$ & $26.09^{\mathrm{a}}$ & $26.34^{\mathrm{a}}$ & 0.027 & 0.48 \\
\hline C18:2n6c & $13.51^{\mathrm{c}}$ & $10.98^{\mathrm{a}}$ & $11.92^{\mathrm{b}}$ & $<0.0001$ & 0.25 \\
\hline C18:3n6 & 0.24 & 0.22 & 0.26 & 0.2301 & 0.01 \\
\hline C20:1 & 3.44 & 3.00 & 3.39 & 0.0648 & 0.14 \\
\hline C18:3n3 & 1.79 & 2.31 & 2.32 & 0.0583 & 0.17 \\
\hline C20:2 & 0.93 & 0.76 & 0.71 & 0.1474 & 0.08 \\
\hline C20:3n6 & $0.66^{\mathrm{b}}$ & $0.48^{\mathrm{a}}$ & $0.51^{\mathrm{a}}$ & $<0.0001$ & 0.03 \\
\hline C22:1n9 & 2.38 & 2.36 & 2.74 & 0.2778 & 0.18 \\
\hline C20:4n6 & 0.99 & 0.88 & 0.86 & 0.1246 & 0.05 \\
\hline C22:2 & 0.08 & 0.11 & 0.06 & 0.4056 & 0.03 \\
\hline C24:1 & 0.18 & 0.14 & 0.15 & 0.434 & 0.02 \\
\hline C20:5n3 & 2.83 & 2.23 & 2.51 & 0.07 & 0.18 \\
\hline C22:6n3 & $7.43^{b}$ & $5.55^{\mathrm{a}}$ & $5.68^{\mathrm{a}}$ & 0.0072 & 0.44 \\
\hline SFA & $29.20^{\mathrm{a}}$ & $34.90^{c}$ & $33.41^{b}$ & $<0.0001$ & 0.43 \\
\hline MUFA & 42.07 & 41.47 & 41.76 & 0.7716 & 0.59 \\
\hline PUFA & $28.73^{b}$ & $23.63^{\mathrm{a}}$ & $24.83^{\mathrm{a}}$ & $<.0001$ & 0.66 \\
\hline$\omega 3$ & $12.38^{\mathrm{b}}$ & $10.23^{\mathrm{a}}$ & $10.52^{\mathrm{a}}$ & 0.0086 & 0.50 \\
\hline$\omega 6$ & $16.36^{c}$ & $13.41^{\mathrm{a}}$ & $14.32^{\mathrm{b}}$ & $<.0001$ & 0.29 \\
\hline$\omega 3: \omega 6$ & 0.76 & 0.76 & 0.74 & 0.7827 & 0.03 \\
\hline $\mathbf{N}$ & 12 & 12 & 12 & & \\
\hline
\end{tabular}

Table 2: EFFECTS OF PLOIDY ON FATTY ACID COMPOSITION OF INTRAMUSCULAR LIPIDS

Percent fatty acid based on relative peak area of all measured fatty acids. LSMeans \pm SEM for 22 individual fatty acids and the total saturated fatty acids (SFA), monounsaturated fatty acids (MUFA), polyunsaturated fatty acids (PUFA), omega-3 fatty acids ( $\omega 3)$, omega- 6 fatty acids ( $\omega 6)$, and omega-3 to omega-6 ratio ( $\omega 3: \omega 6)$. Superscripts indicate significant effects of ploidy. Means with the same letters are not significantly difference $(p>0.05)$. 


\begin{tabular}{llllll}
\hline Fatty acid & 2N & 3NC & 3NP & P-value & $\begin{array}{l}\text { LSMean } \\
\text { Error }\end{array}$ \\
\hline C14:0 & 0.5 & 1.1 & 0.5 & 0.4702 & 0.4 \\
C16:0 & $13.0^{\mathrm{a}}$ & $17.9^{\mathrm{b}}$ & $12.7^{\mathrm{a}}$ & 0.086 & 1.8 \\
C16:1 & 5.6 & 7.2 & 6.0 & 0.5595 & 1.1 \\
C18:0 & 5.3 & 5.0 & 4.7 & 0.8364 & 0.7 \\
C18:1n9c & 35.5 & 36.8 & 42.1 & 0.4335 & 3.7 \\
$\mathbf{C 1 8 : 2 n 6 c}$ & 13.6 & 12.8 & 14.0 & 0.8757 & 0.6 \\
$\mathbf{C 1 8 : 3 n 3}$ & $3.5^{\mathrm{b}}$ & $2.2^{\mathrm{a}}$ & $4.4^{\mathrm{b}}$ & 0.0979 & 0.7 \\
$\mathbf{C 2 0 : 2}$ & 4.4 & 0.2 & 0.5 & 0.1504 & 1.6 \\
$\mathbf{C 2 2 : 1 n 9}$ & 3.4 & 2.3 & 3.0 & 0.5953 & 0.8 \\
$\mathbf{C 2 0 : 4 n 6}$ & 0.3 & 0.2 & 0.0 & 0.4612 & 0.2 \\
$\mathbf{C 2 0 : 5 n 3}$ & 2.1 & 3.0 & 1.7 & 0.3505 & 0.6 \\
$\mathbf{C 2 2 : 6 n 3}$ & 8.6 & 9.4 & 7.7 & 0.5685 & 1.1 \\
$\mathbf{N}$ & 12 & 12 & 12 & & \\
\hline
\end{tabular}

Table 3: EFFECT OF PLOIDY ON INTRAMUSCULAR FATTY ACID COMPOSITION WITHIN TRIGLYCERIDES

Percent fatty acid of all measured fatty acids. LSMean \pm SEM for 12 individual fatty acids. Significance for triglycerides $(\mathrm{P}<0.1)$ is designated by superscripts. Means with the same letters are not significantly difference $(\mathrm{p}>0.1)$.

\begin{tabular}{llllll}
\hline Fatty acid & 2N & 3NC & 3NP & P-value & $\begin{array}{l}\text { LSMean } \\
\text { Error }\end{array}$ \\
\hline C14:0 & 0.5 & 0.5 & 0.3 & 0.6054 & 0.02 \\
C16:0 & 24.8 & 28.7 & 24.3 & 0.7393 & 4.3 \\
C16:1 & 2.6 & 2.7 & 3.4 & 0.7154 & 0.7 \\
C18:0 & 6.8 & 7.7 & 6.2 & 0.6841 & 1.2 \\
C18:1n9c & 22.2 & 14.4 & 25.8 & 0.2917 & 5.1 \\
C18:2n6c & 6.3 & 6.0 & 6.8 & 0.8630 & 1.1 \\
C18:3n3 & 1.0 & 0.7 & 0.9 & 0.8247 & 0.3 \\
C20:2 & 2.7 & 0.6 & 3.6 & 0.4361 & 1.7 \\
C22:1n9 & 0.3 & 1.2 & 0.7 & 0.5899 & 0.6 \\
C20:4n6 & 1.5 & 1.9 & 1.0 & 0.1594 & 0.3 \\
C20:5n3 & 4.7 & 5.3 & 3.5 & 0.3398 & 0.9 \\
C22:6n3 & 23.5 & 28.5 & 21.2 & 0.3435 & 3.6 \\
N & 12 & 12 & 12 & & \\
\hline
\end{tabular}

Table 4: EFFECTS OF PLOIDY ON INTRAMUSCULAR FATTY ACID COMPOSITION WITHIN PHOSPHOLIPIDS

Percent fatty acid of all measured fatty acids. LSMean \pm SEM for 12 individual fatty acids. There was no significant effect of ploidy on phospholipids fatty acid composition. 


\begin{tabular}{lllll}
\hline Fatty acid & Triglycerides & Phospholipids & P-value & $\begin{array}{l}\text { LSMean } \\
\text { Error }\end{array}$ \\
\hline C14:0 & 0.7 & 0.4 & 0.3253 & 0.2 \\
C16:0 & $14.6^{\mathrm{a}}$ & $25.9^{\mathrm{b}}$ & 0.0004 & 1.9 \\
C16:1 & $6.2^{\mathrm{b}}$ & $2.9^{\mathrm{a}}$ & 0.0003 & 0.5 \\
C18:0 & 5.0 & 7.0 & 0.102 & 0.6 \\
C18:1n9c & $38.2^{\mathrm{b}}$ & $20.7^{\mathrm{a}}$ & $<.0001$ & 2.6 \\
C18:2n6c & $13.5^{\mathrm{b}}$ & $6.3^{\mathrm{a}}$ & $<.0001$ & 0.8 \\
C18:3n3 & $3.4^{\mathrm{b}}$ & $0.9^{\mathrm{a}}$ & $<.0001$ & 0.3 \\
C20:2 & 1.7 & 2.3 & 0.2858 & 1.0 \\
C22:1n9 & $2.9^{\mathrm{b}}$ & $0.8^{\mathrm{a}}$ & 0.0039 & 0.4 \\
C20:4n6 & $0.2^{\mathrm{a}}$ & $1.5^{\mathrm{b}}$ & $<.0001$ & 0.1 \\
C20:5n3 & $2.3^{\mathrm{a}}$ & $4.5^{\mathrm{b}}$ & 0.0011 & 0.4 \\
C22:6n3 & $8.6^{\mathrm{a}}$ & $24.4^{\mathrm{b}}$ & $<.0001$ & 1.5 \\
N & 36 & 36 & & \\
\hline Table 5: INTRAMUSCULAR FATTY ACID COMPOSITION AS
\end{tabular}

Table 5: INTRAMUSCULAR FATTY ACID COMPOSITION AS AFFECTED BY LIPID CLASS

Percent fatty acid based on relative peak area of all measured fatty acids. LSMean \pm SEM for 12 individual fatty acids. Superscripts indicate significant effects of type. Means with the same letters are not significantly difference $(\mathrm{p}>0.05)$. 


\section{REFERENCES}

AOAC. 1990. Official Methods of Analysis. 15th ed. Washington DC: Association of Official Analytical Chemists.

Astuarino JF, Sorbera LA, Carrillo M, Zanuy S, Ramos J, Navarro JC, Bromage N .2001. Reproductive performance in male European sea bass fed two PUFA-enriched experimental diets: a comparison with females fed a wet diet. Aquaculture 194:173-190.

Aussanasuwannakul, A., Kenney, P. B., Weber, G. M., Yao, J., Slider, S. D., Manor, M. L., \& Salem, M. 2011. Effect of sexual maturation on growth, fillet composition, and texture of female rainbow trout (Oncorhynchus mykiss) on a high nutritional plane. Aquaculture, 317(1), 79-88.

Bell, J. G., Castell, J. D., Tocher, D. R., MacDonald, F. M., \& Sargent, J. R. 1995. Effects of different dietary arachidonic acid: docosahexaenoic acid ratios on phospholipid fatty acid compositions and prostaglandin production in juvenile turbot (Scophthalmus maximus). Fish Physiology and Biochemistry, 14(2), 139-151.

Bligh, E. G., \& Dyer, W. J. 1959. A rapid method of total lipid extraction and purification. Canadian journal of biochemistry and physiology, 37(8), 911-917.

Boulanger, Y. 1987 Preliminary results on the growth of sterile rainbow trout (triploidy induced by a pressure shock) in fish culture. Proc. Ann. Meet. Aquacult. Assoc. Can. 1, 55-58.

Boyer, R. 2002. Interactive concepts in biochemistry.

Buda, C., Dey, I., Balogh, N., Horvath, L. I., Maderspach, K., Juhasz, M., ... \& Farkas, T. 1994. Structural order of membranes and composition of phospholipids in fish brain cells during thermal acclimatization. Proceedings of the National Academy of Sciences, 91(17), 82348238 .

Calder, P. C. 2010. Omega-3 fatty acids and inflammatory processes. Nutrients, 2(3), 355-374.

Castell, J. D., Lee, D. J., \& Sinnhuber, R. O. 1972. Essential fatty acids in the diet of rainbow trout (Salmo gairdneri): lipid metabolism and fatty acid composition. The Journal of nutrition, 102(1), 93-99.

Chourrout, D., Chevassus, B., Krieg, F., Happe, A., Burger, G., \& Renard, P. 1986. Production of second generation triploid and tetraploid rainbow trout by mating tetraploid males and diploid females - potential of tetraploid fish.Theoretical and Applied Genetics, 72(2), 193206. 
Contreras-Sanchez, W. M., Schreck, C. B., Fitzpatrick, M. S., \& Pereira, C. B. 1998. Effects of stress on the reproductive performance of rainbow trout (Oncorhynchus mykiss). Biology of Reproduction, 58(2), 439-447.

Dey, I., Buda, C., Wiik, T., Halver, J. E., \& Farkas, T. 1993. Molecular and structural composition of phospholipid membranes in livers of marine and freshwater fish in relation to temperature. Proceedings of the National Academy of Sciences, 90(16), 7498-7502.

Fauconneau, B., Andre, S., Chmaitilly, J., Bail, P. Y., Krieg, F., \& Kaushik, S. J. 1997. Control of skeletal muscle fibres and adipose cells size in the flesh of rainbow trout. Journal of Fish Biology, 50(2), 296-314.

Fritshe, K. L., \& Johnston, P. U. 1990. Effect of dietary-linolenic acid on growth, metastasis, fatty acid profile and prostaglandin production of two murine mammary adenocarcinomas. J. Nutr, 120, 1601-1609.

Gilhousen, P. 1980. Energy sources and expenditures in Fraser River sockeye salmon during their spawning migration (Vol. 22). International Pacific Salmon Fisheries Commission.

Haugen, T., Kiessling, A., Olsen, R. E., Rørå, M. B., Slinde, E., \& Nortvedt, R. 2006. Seasonal variations in muscle growth dynamics and selected quality attributes in Atlantic halibut (Hippoglossus hippoglossus L.) fed dietary lipids containing soybean and/or herring oil under different rearing regimes. Aquaculture, 261(2), 565-579.

Hendry, A. P., \& Berg, O. K. 1999. Secondary sexual characters, energy use, senescence, and the cost of reproduction in sockeye salmon. Canadian Journal of Zoology, 77(11), 1663-1675.

Hershberger, W. K., \& Hostuttler, M. A. 2005. Protocols for more effective induction of tetraploid rainbow trout. North American Journal of Aquaculture, 69(4), 367-372.

Hershberger, W.K., Houstuttler, M.A., 2007. Protocols for more effective induction of tetraploid rainbow trout. N. Am. J. Aquac. 69, 367-372.

Horstegen-Schwark, G. 1993. Initation of tetraploid breeding line development in rainbow trout, Oncorhynchus mykiss (Walbaum). Aquaculture and Fisheries Management 24, 641-652.

Lawrie RA. 1991. Meat Science $5^{\text {th }}$ ed. Oxford, Pergamon press.

Lee, E.-H., Chung, B.-G., Kim, J.-S., Ahn, C.-B., Joo, D.-S. and Oh, K.-S. (1989b). Studies on the food components of triploid carp muscle. 2. Lipid components of triploid carp muscle. Bulletin of the Korean Fisheries Society 22, 161-168. 
Mangalassary, S., Dawson, P. L., Rieck, J., \& Han, I. Y. 2004. Thickness and compositional effects on surface heating rate of bologna during in-package pasteurization. Poultry science, 83(8), 1456-1461.

Manor, M. L., Weber, G. M., Cleveland, B. M., \& Kenney, P. B. 2014. Effects of feeding level and sexual maturation on fatty acid composition of energy stores in diploid and triploid rainbow trout (Oncorhynchus mykiss). Aquaculture,418, 17-25.

Manor, M. L., Weber, G. M., Salem, M., Yao, J., Aussanasuwannakul, A., \& Kenney, P. B. 2012. Effect of sexual maturation and triploidy on chemical composition and fatty acid content of energy stores in female rainbow trout, Oncorhynchus mykiss. Aquaculture, 364, 312-321.

Miller, R. K. 2004. Chemical and physical characteristics of meat/palatability. Encyclopedia of meat sciences, 1, 256-266.

Nassour, I., \& Léger, C. L. 1989. Deposition and mobilisation of body fat during sexual maturation in female trout (Salmo gairdneri Richardson). Aquatic living resources, 2(03), 153-159.

Nilsson, K., Ekstrand, B. 1995. Sensory and chemically measured effects of different freeze treatments on the quality of farmed rainbow trout. Journal of Food Quality. 18, 177-191.

Poontawee, K., Werner, C., Müller-Belecke, A., Hörstgen-Schwark, G., \& Wicke, M. 2007. Flesh qualities and muscle fiber characteristics in triploid and diploid rainbow trout. Journal of Applied Ichthyology, 23(3), 273-275.

Purves, W. K., Orians, G. H., Sadava, D., \& Heller, H. C. 2003. Life: The Science of Biology: Volume III: Plants and Animals (Vol. 3). Macmillan.

Ribeiro, C. S., Gomes, A. D., Vieira, V. A. R. O., Tabata, Y. A., Takahashi, N. S., \& Moreira, R. G. 2012. The effect of ploidy on the fatty acid profile during the reproductive cycle of female rainbow trout (Oncorhynchus mykiss). Aquaculture International, 20(6), 11171137.

Salem, M., Kenney, P. B., Rexroad, C. E., \& Yao, J. 2006. Molecular characterization of muscle atrophy and proteolysis associated with spawning in rainbow trout. Comparative Biochemistry and Physiology Part D: Genomics and Proteomics, 1(2), 227-237.

Salze, G., Tocher, D. R., Roy, W. J., \& Robertson, D. A. 2005. Egg quality determinants in cod (Gadus morhua L.): egg performance and lipids in eggs from farmed and wild broodstock. Aquaculture Research, 36(15), 1488-1499.

Satar, E. I., Uysal, E., Ünlü, E., Başhan, M., \& Satar, A. 2012. The effects of seasonal variation on the fatty acid composition of total lipid, phospholipid, and triacylglycerol in the dorsal 
muscle of Capoeta trutta found in the Tigris River (Turkey). Turkish Journal of Biology, 36(1), 113-123.

Saito, M., Kuwada, T., Arai, M., Yamashita, Y., Aoki, T., \& Kunisaki, N. 1997. Changes of the Proximate Composition and Some Minor Constituents of the Muscular Tissue from Cultured Diploid and Triploid Amago during Growth. Fisheries science, 63(4), 639-643.

Smith, S.B., Smith, D.R., Lunt, D.K. 2004. Adipose tissue. In: Jensen, W.K. (Ed.), Encyclopedia of Meat Sciences. Elsevier Ltd., Oxford, pp. 1370-1376.

Sorbera LA, Astuarino JF, Carrillo M, Zanuy S .2001. Effects of polyunsaturated fatty acids and prosta-glandins on oocytes maturation in a marine teleost, the European sea bass (Dicentrarchus labrax). Biol Reprod 64:382-389

Tocher, D. R. 2003. Metabolism and functions of lipids and fatty acids in teleost fish. Reviews in Fisheries Science, 11(2), 107-184.

Wall, R., Ross, R. P., Fitzgerald, G. F., \& Stanton, C. 2010. Fatty acids from fish: the antiinflammatory potential of long-chain omega-3 fatty acids. Nutrition reviews, 68(5), 280289.

Weber, G. M., Hostuttler, M. A., Cleveland, B. M., \& Leeds, T. D. 2014. Growth performance comparison of intercross-triploid, induced triploid, and diploid rainbow trout. Aquaculture, 433, 85-93.

Werner, C.A.R.S.T.E.N., Poontawee, K.E.R.A.T.I.K.O.R.N., Mueller-Belecke, A., HoerstgenSchwark, G., \& Wicke, M.I.C.H.A.E.L. 2008. Flesh characteristics of pan-size triploid and diploid rainbow trout (Oncorhynchus mykiss) reared in a commercial fish farm. ARCHIV FUR TIERZUCHT, 51(1), 71.

Yanes-Roca, C., Rhody, N., Nystrom, M., \& Main, K. L. 2009. Effects of fatty acid composition and spawning season patterns on egg quality and larval survival in common snook (Centropomus undecimalis). Aquaculture, 287(3), 335-340. 


\section{APPENDIX 1}

\section{Lipid Extraction and Fatty Acid Methylation}

\section{Sample preparation:}

1. Intact muscle form—Fillets (excluding belly flap) are skinned, vacuum packed and kept at $-20 \cdot$ C. When lipid extraction is performed, frozen fillets are partially thawed and processed the same as powdered sample preparation.

2. Powder form - Fillets are skinned, cut into small pieces (excluding belly flap), frozen with liquid $\mathrm{N} 2$, and powdered in a Waring blender for 1-2 $\mathrm{min}$. TBHQ $(0.1 \mathrm{~g})$ is added before blending to prevent lipid oxidation. Powdered samples are kept at $-80 \cdot \mathrm{C}$.

\section{Important:}

- Use 35-mL Teflon-lined screw cap glass centrifuge tubes

- Check the condition of tubes and caps for methylation step-No chips or cracks

- Work under hood

- Use glass when working with chloroform or methanol

\section{Instruments:}

1. Hood

2. $60 \cdot \mathrm{C}$ water bath or heating block

3. $90 \cdot \mathrm{C}$ water bath or heating block

4. Manifold and nitrogen gas

5. Centrifuge

6. Vortex

\section{Chemicals:}

1. Trizma/EDTA buffer:

$50 \mathrm{mM}$ Trizma $\mathrm{HCl}: 7.880 \mathrm{~g}$ per $1000 \mathrm{~mL}$ dd water 
1 mM EDTA-disodium salt: $0.372 \mathrm{~g}$ per $1000 \mathrm{~mL}$ dd water

Mix above stock solutions in a beaker, adjust $\mathrm{pH}$ to 7.4 with $5 \mathrm{M}$ or $1 \mathrm{M} \mathrm{NaOH}$, then filter using a 0.2 micron filter storage unit. Buffer is stored at $4^{\circ} \mathrm{C}$.

2. C:M:A (chloroform:absolute methanol: gracial acetic acid) 400:200:3 mL 117

3. 2:1 (chloroform:methanol by volume) e.g. 400:200 mL

4. 4:1 (chloroform:methanol by volume) e.g. 400:100

5. 4\% (w/v) H2SO4 in anhydrous methanol. Must prepare fresh.

6. Chloroform

7. Anhydrous Na2SO4

8. 1-PS Phase separation filters (diameter $9 \mathrm{~cm}$ ). This filter type takes water out off solution, thus filtered solution is water free.

9. Glass wool

10. Iso-octane. Filter using a 0.45 micron filter storage unit.

\section{Lipid extraction step:}

2. Weigh powdered sample in a 35-mL Teflon lined screw cap glass centrifuge tube.

3. Add $5 \mathrm{~mL}$ Trizma/EDTA, then vortex for $60 \mathrm{sec}$.

4. Add $20 \mathrm{~mL}$ C:M:A, then vortex vigorously twice (30 sec x 2).

5. Hold tubes at room temperature for $10 \mathrm{~min}$.

6. Centrifuge at $900 \times \mathrm{g}(4000 \mathrm{rpm}), 10^{\circ} \mathrm{C}$ for $10 \mathrm{~min}$.

7. Transfer all lower layer with glass Pasteur pipet over 1-PS filter. Collect filtered sample in a 35-mL Teflon lined screw cap glass centrifuge tube. (Pre-rinse filter paper 3 times with 5 mL 2:1 C:M each to remove trace silicone residue, and put away filtrate.)

8. Add $10 \mathrm{~mL}$ 4:1 C:M to the upper layer, vortex for $15 \mathrm{sec}$, and centrifuge at $900 \mathrm{x} g$ (4000 $\mathrm{rpm}), 10^{\circ} \mathrm{C}$ for $10 \mathrm{~min}$. 
9. Again transfer all lower layer over 1-PS filter. Rinse filter paper with $5 \mathrm{~mL} \mathrm{2:1} \mathrm{C:M}$ after the filtrate has gone. Take filter paper out, and rinse inside and outside of funnel with 1 pipett of 2:1 C:M. (Filtrated sample can be stored at $0-5^{\circ} \mathrm{C}$ for $1-3$ days.)

10. Blow down under nitrogen gas to dry sample in $60^{\circ} \mathrm{C}$ water bath. Nitrogen gas outlet should be close to liquid surface. (It takes around 60-75 mi. Completely dry sample does not have a smell of acetic acid.)

118

\section{Methylation step:}

1. Add $4 \mathrm{~mL}$ of $4 \% \mathrm{H} 2 \mathrm{SO} 4$ solution. (CAP THIGHTLY-NO LEAKING)

2. Heat in water bath or heating block at $90^{\circ} \mathrm{C}$ for $60 \mathrm{~min}$.

3. Cool in to room temperature then add $3 \mathrm{~mL}$ dd water (to stop reaction).

4. Add $8 \mathrm{~mL}$ chloroform, then vortex for $30 \mathrm{sec}$.

5. Centrifuge at $900 \times \mathrm{g}(4000 \mathrm{rpm}), 10^{\circ} \mathrm{C}$ for $10 \mathrm{~min}$.

6. Transfer the bottom layer (chloroform layer) through a Na2SO4 filled glass Pasteur pipet into 10-mL glass tube. Collect filtered sample in a 10-mL screw cap glass tube. (Fill Pasteur pipet with glasswool first, then with around 1 inch of Na2SO4 layer. Pre-rinse with 1 pipett of chloroform and put away filtrate). Rinse the filter layer with a half pipett of chloroform to wash out sample that trapped in the filter layer. Before take the filter out, rinse the outside with a little bit of chloroform.

7. Blow down under nitrogen gas in $60^{\circ} \mathrm{C}$ water bath. Nitrogen gas outlet should be close to liquid surface. (It takes around 20-25 min. Completely dry sample does not have a smell of chloroform.)

8. Resuspend dried sample in $3 \mathrm{~mL}$ of filtered isooctane and keep at $-20^{\circ} \mathrm{C}$ or inject into $\mathrm{GC}$ 


\title{
APPENDIX 2
}

\section{Calculations for Proximate Analysis}

\author{
A. Dry Weight \\ $D r y W t=($ Pan + DryWt $)-$ PanWt \\ B. Percent Moisture \\ $\%$ Moisture $=100-\%$ DryWt \\ C. Percent Crude Fat \\ $\%$ Fat $=\left(\frac{(\text { SampleWt }- \text { DryWt })-\text { gMoisture }}{\text { SampleWt }}\right) \times 100$ \\ D. Percent Crude Protein \\ $\% \operatorname{Pr}$ otein $=\left(\frac{(0.1 \times 14.01 \times 6.25 \times \text { mLofAcid })}{(\text { SampleWt } \times 1000)}\right) \times 100$ \\ E. Percent Ash \\ $\% A s h=\left(\frac{(\text { CrucibleWt }- \text { AshWt })}{\text { SampleWt }}\right) \times 100$
}


APPENDIX 3

\begin{tabular}{llllll}
\hline Fatty acid & 2N & 3NC & 3NP & P-value & $\begin{array}{l}\text { LSMean } \\
\text { Error }\end{array}$ \\
\hline C12:0 & 0.004 & 0.007 & 0.005 & 0.0656 & 0.0009 \\
C14:0 & 0.50 & 0.54 & 0.46 & 0.6786 & 0.07 \\
C15:0 & 0.03 & 0.03 & 0.03 & 0.6849 & 0.005 \\
C16:0 & 2.65 & 2.61 & 2.11 & 0.4514 & 0.33 \\
C16:1 & 1.71 & 1.68 & 1.31 & 0.3743 & 0.22 \\
C17:0 & 0.03 & 0.02 & 0.02 & 0.1121 & 0.004 \\
C17:1 & $0.04^{\mathrm{b}}$ & $0.03^{\mathrm{a}}$ & $0.03^{\mathrm{a}}$ & 0.0186 & 0.004 \\
C18:0 & 0.62 & 0.48 & 0.43 & 0.1982 & 0.07 \\
C18:1n9t & $0.02^{\mathrm{b}}$ & $0.01^{\mathrm{a}}$ & $0.01^{\mathrm{a}}$ & 0.0003 & 0.002 \\
C18:1n9c & 4.01 & 2.98 & 2.56 & 0.1094 & 0.48 \\
C18:2n6c & $2.08^{\mathrm{b}}$ & $1.34^{\mathrm{a}}$ & $1.22^{\mathrm{a}}$ & 0.0305 & 0.24 \\
C18:3n6 & $0.04^{\mathrm{b}}$ & $0.03^{\mathrm{a}}$ & $0.03^{\mathrm{a}}$ & 0.0391 & 0.004 \\
C20:1 & 0.86 & 0.59 & 0.57 & 0.0961 & 0.10 \\
C18:3n3 & 0.25 & 0.22 & 0.18 & 0.4015 & 0.04 \\
C20:2 & 0.16 & 0.10 & 0.08 & 0.0766 & 0.03 \\
C20:3n6 & $0.10^{\mathrm{b}}$ & $0.06^{\mathrm{a}}$ & $0.05^{\mathrm{a}}$ & 0.0085 & 0.01 \\
C22:1n9 & 0.23 & 0.18 & 0.17 & 0.4007 & 0.03 \\
C20:4n6 & 0.16 & 0.11 & 0.09 & 0.0713 & 0.02 \\
C22:2 & 0.02 & 0.01 & 0.01 & 0.1811 & 0.003 \\
C24:1 & 0.03 & 0.01 & 0.02 & 0.0811 & 0.004 \\
C20:5n3 & $0.37^{\mathrm{b}}$ & $0.25^{\mathrm{a}}$ & $0.23^{\mathrm{a}}$ & 0.0381 & 0.04 \\
C22:6n3 & $1.99^{\mathrm{b}}$ & $1.09^{\mathrm{a}}$ & $1.01^{\mathrm{a}}$ & 0.0124 & 0.24 \\
& & & & & \\
SFA & 3.84 & 3.70 & 3.06 & 0.4776 & 0.48 \\
MUFA & 6.89 & 5.47 & 4.67 & 0.1762 & 0.83 \\
PUFA & $5.17^{\mathrm{b}}$ & $3.19^{\mathrm{a}}$ & $2.92^{\mathrm{a}}$ & 0.0238 & 0.60 \\
$\mathbf{\omega 3}$ & $2.61^{\mathrm{b}}$ & $1.55^{\mathrm{a}}$ & $1.43^{\mathrm{a}}$ & 0.0204 & 0.31 \\
$\mathbf{\omega 6}$ & $2.40^{\mathrm{b}}$ & $1.54^{\mathrm{a}}$ & $1.40^{\mathrm{a}}$ & 0.0306 & 0.27 \\
$\mathbf{\omega 3 : 0 6}$ & 1.10 & 1.07 & 1.02 & 0.5329 & 0.05 \\
$\mathbf{N}$ & 12 & 12 & 12 & & \\
\hline $\mathbf{E F}$ & & 12 & & &
\end{tabular}

EFFECTS OF PLOIDY ON FATTY ACID COMPOSITION OF INTRAMUSCULAR LIPIDS BASED ON mg/g

Fatty acids are represented as $\mathrm{mg} / \mathrm{g}$. LSMeans \pm SEM for 22 individual fatty acids and the total saturated fatty acids (SFA), monounsaturated fatty acids (MUFA), polyunsaturated fatty acids (PUFA), omega-3 fatty acids ( $\omega 3)$, omega-6 fatty acids $(\omega 6)$, and omega-3 to omega-6 ratio ( $\omega 3: \omega 6)$. Superscripts indicate significant effects of ploidy. Means with the same letters are not significantly difference $(\mathrm{p}>0.05)$. Calculated by individual fish relative peak percent by the percent of crude fat in the fish. 